Clemson University

TigerPrints

$10-2011$

Teachers' Perceptions of Integrating Information and

Communication Technologies Into Literacy Instruction: A National Survey in the United States

David Reinking

Amy Hutchison

Follow this and additional works at: https://tigerprints.clemson.edu/eugene_pubs

Part of the Language and Literacy Education Commons 


\title{
Teachers' Perceptions of Integrating Information and Communication Technologies Into Literacy Instruction: A National Survey in the United States
}

\author{
Amy Hutchison \\ lowa State University, USA \\ David Reinking \\ Clemson University, South Carolina, USA
}

\section{A B S T R A C T}

This research explores literacy teachers' perceptions of integrating information communication technologies (ICTs) into literacy instruction. To this end, a national survey of 1,441 literacy teachers in the United States was conducted. The survey provided data concerning the types and levels of reported availability and use of ICTs, beliefs about the importance of integrating ICTs into literacy instruction, and perceived obstacles to doing so. The analysis of data included descriptive statistics, an exploratory factor analysis, and a path analysis used to test a model hypothesizing a relation between teachers' perceived importance of technology and reported levels of integration. Results revealed relatively low levels of curricular integration, consistent perceptions about obstacles to integration, and technological rather than curricular definitions of ICTs and of integration. The path analysis suggested several characteristics and influences associated with higher levels of integration and use. The findings advance understanding of the extent to which ICTs are being integrated into literacy instruction and what factors should be considered toward profitably increasing integration consistent with expanding definitions of literacy.

$\mathrm{D}$ igital forms of communication, which are often referred to collectively as information and communication technologies (ICTs), have entered the mainstream of everyday literacy. For example, since 2000 the Pew Research Center's Pew Internet \& American Life Project has disseminated numerous reports that document the increasing use of the Internet and how its use has transformed diverse areas of personal and professional life (see www .pewinternet.org/topics.asp?c=4). Responding to these trends, prominent professional organizations promoting the development of literacy in schools have issued calls for educators to integrate ICTs and associated forms of digital reading and writing into their instruction. For example, the International Reading Association (IRA) has adopted a position statement that takes the following stance:
To become fully literate in today's world, students must become proficient in the new literacies of 21st-century technologies. As a result, literacy educators have a responsibility to effectively integrate these new technologies into the curriculum, preparing students for the literacy future they deserve. (IRA, 2009, n.p.)

Likewise, the National Council of Teachers of English (NCTE) has 4 position statements, 4 sets of guidelines, and 11 resolutions related to ICTs, including standards for integrating them into instruction (see www.ncte .org).

Several premises underlie these calls to integrate ICTs into literacy instruction and establish the need for and the focus of the present study. First, literacy teachers are expected to provide foundational skills, strategies, and dispositions for reading and writing in 
the dominant modes and genres of communication employed in academic learning and daily life. Although there are many opportunities to authentically apply and practice these skills, strategies, and dispositions in other academic subjects, literacy teachers are specifically charged with developing all mainstream aspects of literacy, increasingly including those involving ICTs. Second, the curriculum of literacy instruction includes opportunities for using ICTs to enhance content specific to the language arts (e.g., using the Internet to find background on an author or the setting of a novel). These two premises are reflected in the recently released national common core state standards for language arts in the United States (www.corestan dards.org/the-standards), which include attention to digital forms of reading and writing and reaffirm the fundamental role of the language arts in supporting literate activity in other curricular areas.

Third, despite prominent calls for integrating ICTs into instruction and the widespread availability of Internet access in schools (in 2006, Wells \& Lewis reported access approaching 100\%), many scholars have argued that integration has been minimal or superficial and has not kept pace with developments outside of classrooms and schools, especially in the United States (e.g., Cuban, 2001, Leu 2006). Some empirical evidence suggests that integration has been relatively sparse among literacy teachers (Karchmer, 2001; Stolle, 2008). Indeed, a perceived lack of adequate integration is the implicit rationale for IRA and NGTE to stress the need to integrate ICTs into instruction. However, data have not been collected on a large scale to determine-from the standpoint of literacy teachers - the extent to which integration has occurred, what obstacles inhibit integration, how teachers conceptualize ICTs, and so forth. Neither are there data suggesting what characteristics, perceptions, or situations pertaining to the use of ICTs are associated with lower or higher levels of reported integration.

A fourth premise is that ICTs provide unique affordances for reading and writing and thus they require unique skills, strategies, and dispositions that may build upon, but also exceed, those associated with conventional printed forms of communication. This premise is supported theoretically and empirically in the literature substantiating the differences between digital and printed texts (e.g., Leu \& Reinking, 1996; McEneaney, 2006; Reinking, 1992, 1998, 2001) and by prominent arguments that digital forms of reading and writing significantly alter and expand definitions of literacy (e.g., Coiro, Knobel, Lankshear \& Leu, 2008; Kress, 2003; Lankshear \& Knobel, 2003). Thus, a failure to integrate ICTs appropriately into language arts instruction risks leaving today's generation of students unprepared for mainstream reading and writing activities that are increasingly prominent in and out of academic contexts (Leu, Kinzer, Coiro, \& Cammack, 2004).

A final premise is that the burden of integrating ICTs into literacy instruction does not fall solely on literacy teachers. For example, the IRA position statement calls for research that not only informs practitioners' understandings of integration but also policymakers and those involved in pre- and inservice education who are in a position to support efforts to facilitate integration. However, the research that might provide such guidance is relatively limited. There has been no widespread, systematic effort to determine how teachers, who must be in the vanguard of integrating ICTs into literacy instruction, view the relevant issues. For example, although a variety of obstacles inhibiting the integration of ICTs into instruction have been identified in the literature, little is known about what literacy teachers themselves perceive the obstacles to be. There are no data broadly characterizing teachers' beliefs about the importance of integrating ICTs into literacy instruction (e.g., Are they being convinced by the calls for such integration?) or about the ways in which they conceptualize ICTs in relation to their instruction. Neither do we know whether certain perceptions, beliefs, and practices are associated with more or less integration of ICTs. The lack of data pertaining to such questions is especially unfortunate because teachers' beliefs have consistently been identified as related to the extent to which they integrate ICTs into their instruction (Bruce \& Rubin, 1993; Clark \& Peterson, 1986; Ertmer, 2005; Hughes, Kerr, \& Ooms, 2005; Windschitl \& Sahl, 2002; Zhao, Pugh, Sheldon, \& Byers, 2002).

In light of these premises, the purposes of the present study were to (a) characterize literacy teachers' perceptions about integrating ICTs into instruction; (b) clarify and extend findings from previous research pertaining to integrating ICTs into literacy instruction; (c) assist policymakers, education leaders, and those involved with professional development in efforts to facilitate the integration of ICTs into instruction; and (d) create a benchmark against which evolving trends might be compared in the future. Specifically, we developed and disseminated to literacy teachers in the United States an online survey to address the following questions:

1. Do literacy teachers report that necessary or useful technologies are available to facilitate the integration of ICTs into instruction, and do they have the technological support to assist with the use of those technologies?

2. Which ICTs do literacy teachers believe are important for literacy instruction, and how frequently do they report using them? 
3. How do literacy teachers conceptualize the integration of ICTs into their instruction? Do their conceptions align more with superficial technological or substantive curricular integration (as explained subsequently in this manuscript)?

4. What are literacy teachers' perceptions about the role and benefit of using technology in literacy instruction?

5. What do literacy teachers perceive to be the obstacles to integrating ICTs into literacy instruction?

6. What characteristics or beliefs are associated with more or less integration of ICTs? In other words, what factors predict teachers' reported integration of ICTs?

\section{Background}

Because there are no current data addressing these questions on a large scale in the United States, our intent was to create a broad backdrop for more narrowly focused research in the future. We wish to note that we previously reported preliminary data from the survey regarding the question about literacy teachers' perceptions of obstacles to integrating ICTs (Hutchison \& Reinking, 2010). Those data are summarized again in the present report because conclusions and interpretations from the previous report are extended and refined in the context of results from the entire survey. The previously reported data about obstacles to integration also illuminate the results and conclusions pertaining to the other research questions addressed in the present study.

\section{Defining Integration}

Integrating ICTs into literacy instruction is not a unidimensional concept. In the literature, a distinction is typically made between simply using ICTs in a perfunctory way to replicate existing instruction aimed at goals for conventional reading instruction, such as using a digital projector to display a website providing information about the author of a novel, and using ICTs to address new instructional goals, such as how to find information on the Internet (see Dockstader, 1999). Reinking, Labbo, and McKenna (2000) used the Piagetian concepts of assimilation and accommodation to highlight that distinction, arguing that teachers might move through a developmental process of assimilating ICTs to serve conventional instructional goals but eventually accommodating them substantively into their conceptions of literacy, thus adopting expanded goals for instruction. That distinction is consistent with the literature suggesting that technology is less likely to be integrated, or integrated authentically and effectively, when teachers conceptualize the integration of technology as separate from the curriculum. Indeed, Harris, Mishra, and Koehler (2009) argued that authentic curricular integration might entail complex and dynamic interactions between technology, pedagogy, and content knowledge. Labbo and Reinking (1999) proposed a hierarchy corresponding to that development. Arguing that integrating ICTs in literacy research and instruction involves multiple realities, they identified the following progression:

1. Acquiring digital technology

2. Employing it to teach conventional instructional goals

3. Allowing it to transform instruction

4. Adopting new instructional goals consistent with new forms of reading and writing

5. Empowering students

Drawing on these perspectives, we developed the survey to distinguish between what we refer to broadly as technological integration and curricular integration. Technological integration is more superficial, corresponding to assimilating ICTs (Reinking et al., 2000) and the lower levels of Labbo and Reinking's (1999) multiple realities. Technological integration reflects a stance that views ICTs as separate from, or not fully integrated into, the curriculum. Curricular integration, on the other hand, is associated with accommodation and higher levels, such as teaching specific skills related to using the Internet, and reflects a stance that views ICTs as integral to the curriculum, as called for in the IRA position statement indentifying 21st-century literacy skills. For example, on the survey we queried teachers about the extent to which they believed elements of Leu et al.'s (2004) instructional categories were included in their definition of integration and the extent to which they were engaged in such instruction.

\section{Previous Research on Integration}

Previous research relevant to understanding the extent to which literacy teachers are integrating ICTs into instruction is characterized by one or more of the following limitations: (a) integration is studied across several curricular areas, (b) no distinction is made between more shallow technological and deeper curricular integration, (c) only a few teachers in a single school or district are studied, or (d) the focus is on teachers identified as being on the leading edge of integrating technology into instruction. For example, Karchmer (2001) analyzed data from semistructured e-mail interviews with 13 teachers who taught in kindergarten through 12th grade and from their journals 
that reflected on how they integrated technology into instruction. Although the teachers expressed understanding of and commitment to what we call curricular integration, Karchmer concluded that such integration was minimal. Importantly, these teachers were selected to participate in the study from a pool of 31 teachers who were nominated as being exemplary in integrating technology into literacy instruction. Thus, this study did not reveal the perceptions of a broad cross-section of literacy teachers with varying stances toward and experiences with ICTs.

More recently, Stolle (2008) conducted observations of 16 secondary teachers in various content areas, accompanied by focus-group interviews, to investigate how they viewed the effects of ICTs on teaching and learning, and the relation between those views and their teaching practices related to literacy. She concluded that tensions, ambiguities, and fears teachers face about access to technology, knowledge of its use, and who benefits from using it limit the extent to which ICTs are integrated into instruction. As a consequence, "teachers are limited in their ability to envision beyond what they already know and do" (p. 65), and they "simply find ways to use ICTs to complete tasks they previously did without ICTs" (p. 66). The present investigation provides larger scale national data to determine if such findings and conclusions are pervasive among a broad spectrum of literacy teachers.

\section{Obstacles to Integration}

There is little consensus about what may inhibit the integration of ICTs into instruction in general or into literacy instruction in particular. Possible obstacles have been studied using qualitative methods (Honan, 2008; Kist, 2007; Stolle, 2008; Warschauer, Knobel, \& Stone, 2004; Zhao et al., 2002), mixed methods (Bauer \& Kenton, 2005), and surveys (National Center for Educational Statistics, 2005; United States Department of Education, 2003). However, there is little consistency across these studies, suggesting that small-scale studies, often across diverse school subjects, do not provide a complete or reliable identification of the obstacles literacy teachers perceive as impeding integration of ICTs into instruction. Further, the range of factors considered is often limited in individual studies.

Thus, one goal of the survey was to reveal what obstacles literacy teachers believe inhibit integration of ICTs into literacy instruction. To address that goal, we developed an item for the survey that listed 21 potential obstacles to integration and asked respondents to indicate the extent to which they perceived each to be an obstacle. Seventeen of the obstacles were drawn from a systematic review of the literature, and four were drawn from our experience in working with literacy teachers to integrate ICTs into instruction (see Hutchison \& Reinking, 2010).

\section{Teachers' Perceptions and Beliefs}

Teachers' perceptions of integrating ICTs into instruction represent another potential obstacle to integration. That is, if teachers have shallow definitions or incomplete perceptions of integrating ICTs into instruction - or perhaps even oppositional stances - they are not likely to achieve a more authentic curricular integration of IGTs. That theme is common in the literature. For example, Ertmer (2005) noted,

\begin{abstract}
Ultimately, the decision regarding whether and how to use technology for instruction rests on the shoulders of classroom teachers. If educators are to achieve fundamental, or second order, changes in classroom teaching practices, we need to examine teachers themselves and the beliefs they hold about teaching, learning, and technology. (p. 27)

Further, there is ample evidence that teachers' beliefs, including their beliefs about their own efficacy (see Ertmer \& Ottenbreit-Leftwich, 2010) in integrating technology into instruction, play a predominant role in how they conceptualize and use computer-based technologies in their teaching (Bruce \& Rubin, 1993; Clark \& Peterson, 1986; Ertmer, 2005; Hughes et al, 2005; Windschitl \& Sahl, 2002; Zhao et al., 2002). For example, Hughes et al. (2005) determined that the more teachers see the connection between technology and the subject content they teach, the more likely they are to develop a technology-supported pedagogy. Thus, one of the goals of the current study was to gain an understanding of how literacy teachers define integrating ICTs into their instruction and how they perceive the importance of doing so.
\end{abstract}

\section{Factors Associated With Integrating ICTs Into Instruction}

There have been no studies specifically addressing what factors might be associated with the level and type of teachers' activities aimed at integrating ICTs into literacy instruction. However, knowing such distinctions may enlighten teachers, theoretically and practically, about how to facilitate integration of ICTs into literacy instruction. Nonetheless, there is some research that suggests a starting point for considering what the key factors might be. For example, researchers have investigated the pedagogical beliefs and environmental factors that seem to influence teachers' integration of ICTs (e.g., Becker, 1994; Ertmer, Gopalakrishnan, \& Ross, 2001; Scott, Chovanec, \& Young, 1993). Likewise, Garner and Gillingham (1996), based on six case studies of teachers who were engaging their students with digital technologies during literacy 
activities, reported that the teachers seemed to be student-centered, active seekers of alternatives to their current practice, and they were apt to see technology as a means to an end. The present study examined on a larger scale what reported perceptions, beliefs, and uses might be related to literacy teachers' reported levels of integrating ICTs into instruction. Specifically, we used the survey data to develop and test a model that predicts reported levels of integration. One factor included in that model is the role of professional development, to which we now turn.

\section{The Role of Professional Development}

Some studies have suggested that a lack of appropriate professional development is one of the prominent reasons that teachers do not integrate technology into their curriculum (Bauer \& Kenton, 2005; Stolle, 2008). It seems logical to assume that professional development aimed at helping teachers understand and integrate ICTs into instruction is useful and necessary given that the evolution of ICTs has been rapid. Additionally, the necessary adaptations of instruction are potentially substantial (Leu, 2006). There are data supporting that view, although none specifically pertaining to literacy teachers (e.g., Becker, 1999; Fatemi, 1999; Penuel, Boscardin, Masyn, \& Crawford, 2007). Yet there is no clear empirical evidence about what approach to or what content provided through professional development might effectively advance teachers' integration of ICTs into curriculum and instruction. Although the methodology of the present investigation does not address those issues directly, it does provide data concerning teachers' views about professional development and what role those views may play in a model predicting levels of integration, which might inform the direction and content of professional development aimed at facilitating integration. For example, if teachers' definitions and perceptions of ICTs are not conducive to integration (e.g., seeing it as separate from the curriculum), then those views might be an appropriate starting point for professional development. If, on the other hand, that issue is moot, then professional development might emphasize more practical issues of implementation. Thus, understanding literacy teachers' perceptions about integrating ICTs into instruction, and which perceptions and reported uses are associated with higher levels of integration, may inform professional development.

\section{Method}

\section{Participants}

The sample for this survey was drawn from teachers in the United States who are members of a state or local council of the IRA. That population was selected because (a) members are predominantly literacy educators, the target population of this study; (b) every state in the United States has a state affiliate comprised of local councils, thus representing the potential for a national sample, but with diversity in grade levels and demographic profiles such as teaching experience; and (c) many, but not all, of the state affiliates have e-mail distribution lists, or they have other means available to disseminate information about an online survey. In a few states where there were obstacles to disseminating the survey through IRA channels, respondents were contacted through similar organizations with listservs such as the Connecticut Association for Reading and the weekly e-mail of Enhancing Missouri's Networked Teaching Strategies.

Table 1 provides a profile of respondents to the survey. As noted, 31 states are represented in the survey from every region of the United States, with states and number of participants grouped in accordance with national regions designated by the United States Census Bureau. To determine if the profile of the survey's respondents was consistent with the profile of the IRA membership, we obtained demographic data from IRA headquarters (Anne Fullerton, personal communication, November 19, 2010). Comparing data from the IRA membership that overlapped with the survey revealed the following comparisons for level taught (survey values, in parentheses, follow IRA data): teaching in kindergarten through grade $6=63.7 \%(53.2 \%)$; teaching in middle school $=8.9 \%(30.2 \%)$; teaching in high school $=5.6 \%(4.0 \%)$. Respondents to the survey paralleled relatively closely the IRA membership except at the middle school level. It may be that the issues identified in the survey were more relevant to middle school teachers, thus generating a higher response from those teachers.

Likewise, we compared the teaching experience of the IRA membership to that of respondents to the survey, which resulted in the following comparisons (IRA percentages are followed by survey percentages in parentheses): $0-5$ years, $10.1 \% \quad(18.9 \%) ; 6-10$ years, $12.4 \%$ (16.7\%); $11-20$ years $27.3 \%$ (30.9\%); and more than 21 years, $50.2 \%(33.5 \%)$. The percentage of respondents at each level of experience was somewhat higher than the IRA membership, except for teachers with more than 21 years experience, which had a lower percentage.

Participants' rating of their own capabilities in using ICTs indicated that $85 \%$ believed their general capabilities were developed to a moderate (51\%) or to a large $(34 \%)$ extent, although interestingly, they believed that the extent of their capabilities to use ICTs for instruction was somewhat lower. That is, $15 \%$ of participants indicated that their general capabilities were developed not at all $(1 \%)$ or to a small 


\section{Table 1. Profile of Participants}

\begin{tabular}{|c|c|c|}
\hline $\begin{array}{l}\text { Professional experience } \\
\text { and demographics }\end{array}$ & $\begin{array}{l}\text { Number of } \\
\text { respondents }\end{array}$ & $\begin{array}{l}\text { Percentage of } \\
\text { respondents }\end{array}$ \\
\hline \multicolumn{3}{|l|}{ Grade level taught } \\
\hline $\mathrm{K}-3$ & 470 & 32.6 \\
\hline $4-6$ & 297 & 20.6 \\
\hline $7-9$ & 435 & 30.2 \\
\hline $10-12^{\mathrm{a}}$ & 57 & 4.0 \\
\hline Specialist/other & 182 & 12.6 \\
\hline \multicolumn{3}{|l|}{ Teach language arts } \\
\hline Yes & 1,321 & 91.7 \\
\hline No & 120 & 8.3 \\
\hline \multicolumn{3}{|c|}{ Teaching experience (years) } \\
\hline $0-5$ & 272 & 18.9 \\
\hline $6-10$ & 240 & 16.7 \\
\hline $11-15$ & 232 & 16.1 \\
\hline $16-20$ & 213 & 14.8 \\
\hline $21-25$ & 162 & 11.2 \\
\hline 26 or more & 322 & 22.3 \\
\hline \multicolumn{3}{|l|}{ Age } \\
\hline $20-25$ & 87 & 6.0 \\
\hline $26-30$ & 123 & 9.0 \\
\hline $31-35$ & 126 & 9.0 \\
\hline $36-40$ & 154 & 10.7 \\
\hline $41-45$ & 172 & 12.0 \\
\hline $46-50$ & 183 & 12.7 \\
\hline $51-55$ & 263 & 18.2 \\
\hline $56-60$ & 213 & 14.8 \\
\hline$>60$ & 120 & 8.0 \\
\hline \multicolumn{3}{|c|}{ Region of residence in the United States } \\
\hline Northeast & 117 & 8.1 \\
\hline Northwest & 124 & 8.6 \\
\hline Midwest & 311 & 21.6 \\
\hline Southeast & 324 & 22.5 \\
\hline Southwest & 111 & 7.7 \\
\hline West & 454 & 31.5 \\
\hline \multicolumn{3}{|c|}{ Capability in using ICTs in general } \\
\hline Not at all & 16 & 1.1 \\
\hline Small extent & 202 & 14.0 \\
\hline Moderate extent & 733 & 51.0 \\
\hline Large extent & 486 & 33.8 \\
\hline NA & 2 & $<0.1$ \\
\hline \multicolumn{3}{|c|}{ Capability in using ICTs for instruction } \\
\hline Not at all & 66 & 4.6 \\
\hline Small extent & 356 & 24.7 \\
\hline Moderate extent & 675 & 46.8 \\
\hline Large extent & 339 & 23.5 \\
\hline NA & 4 & $<0.1$ \\
\hline
\end{tabular}

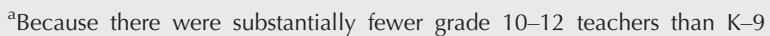
teachers (see Table 1), we conducted an analysis to determine if the results would be statistically different without grade 10-12 teachers. We ran separate correlations for these respective groups for each of the factors established in the exploratory factor analysis. The correlations for each group of teachers followed virtually the same direction and pattern. Further, all of the factors identified when the analysis was conducted with both groups together remained significantly correlated, and all but one of the items were correlated in the same direction. Thus, we determined that the results and conclusions would not be affected by removing the grade 10-12 teachers from the analysis.

extent $(14 \%)$, whereas twice that percentage indicated that their capabilities for using ICTs in instruction were developed not at all $(5 \%)$ or to a small extent $(25 \%)$.

\section{Development and Validation of the Survey}

The development and validation of the online survey followed procedures and recommendations in the literature on survey development (Dillman, 2007; Rea \& Parker, 2005), including the development of online surveys (Sue \& Ritter, 2007). The development of the survey began by establishing the constructs that would be surveyed (Rea \& Parker, 2005). These constructs (reported in Table 2) were derived from the research questions and informed by the available literature reviewed previously in this article.

An initial pool of survey items for each construct was developed. A focus group consisting of three classroom teachers was then consulted about all items to obtain feedback from representatives of the group for whom the survey was intended (Rea \& Parker, 2005). Teachers were selected to represent a range of ICT use, including low, medium, and high levels of ICT integration based on the teachers' self-report and the researchers' experience working with the teachers during a previous, unrelated research study. The survey items were revised based on feedback from the focusgroup meeting with the teachers. For example, several additional examples of ICTs were noted during the focus-group meeting, and additional questions were generated to inquire about those ICTs. In addition, clarifications in terminology were made to the survey based on teachers' input. After revision, the survey was converted to an online format using Survey Monkey (www.surveymonkey.com), a widely used application for developing online surveys.

To enhance validity and increase refinement of the survey, the initial survey was piloted. The pilot survey consisted of 86 items based on the research questions, survey constructs, relevant literature, and focus-group results, and was distributed online using Survey Monkey. A link to the survey and a request for participation were e-mailed to a convenience sample of 100 kindergarten through high school teachers in the researchers' home state. Ninety-two completed surveys were received. The sample for the pilot survey roughly resembled that of the final survey, with 29 teachers of grades $\mathrm{K}-3,45$ teachers of grades $4-6$, and 18 teachers of grades 7-12. Item analyses were conducted on the items hypothesized to represent the constructs used to design the survey. Cronbach's $\alpha$ was computed to determine internal consistency, and values ranged from .82 to .96 for the constructs guiding development of the survey. However, based on survey responses to the initial draft, feedback from the focus group, and problems that arose while validating the survey, several items were revised for clarity. For example, the word year was changed to academic year to clarify the time span to which we referred. In addition, we added specific 
Table 2. Survey Constructs and Items

\begin{tabular}{|c|c|c|c|}
\hline Survey construct & Representative item & $\begin{array}{l}\text { Numbered items } \\
\text { from survey }^{b}\end{array}$ & Response format \\
\hline Extent of ICT integration ${ }^{a}$ & $\begin{array}{l}\text { To what extent do you present students in } \\
\text { your typical reading or language arts class } \\
\text { with online work that involves using } \\
\text { computers or the Internet in the following } \\
\text { ways? } \\
\text {-Publishing information on a wiki or blog (etc.) }\end{array}$ & $3 \mathrm{~A}-\mathrm{K}, 4 \mathrm{~L}-\mathrm{R}$ & Likert scale \\
\hline Perceived importance of $\mathrm{ICTs}^{\mathrm{a}}$ & $\begin{array}{l}\text { To what extent do you feel the following } \\
\text { activities would be important to your literacy } \\
\text { instruction, assuming they were available? } \\
\text {-Publishing information on a wiki or blog (etc.) }\end{array}$ & $5 \mathrm{~A}-\mathrm{K}, 6 \mathrm{~L}-\mathrm{R}$ & Likert scale \\
\hline Competency with ICTs ${ }^{\text {a }}$ & $\begin{array}{l}\text { To what extent are you skilled at using digital } \\
\text { technology for instruction? }\end{array}$ & $7-9,33$ & Likert scale \\
\hline Obstacles to integration $^{\text {a }}$ & $\begin{array}{l}\text { Please indicate the extent to which you } \\
\text { believe the following are obstacles to } \\
\text { integrating technology into your literacy/ } \\
\text { language arts instruction: } \\
\text { I don't think technology is reliable (etc.) }\end{array}$ & $12 \mathrm{~A}-\mathrm{H}, 13 \mathrm{~A}-\mathrm{G}, 14 \mathrm{~A}-\mathrm{G}$ & Likert scale \\
\hline Stance toward technology ${ }^{\text {a }}$ & $\begin{array}{l}\text { Choose the statement below that best } \\
\text { describes how you view technology as it } \\
\text { relates to language arts instruction. }\end{array}$ & $10,19-20,37$ & Likert scale \\
\hline Support for using/integrating ICTs & $\begin{array}{l}\text { What kind of technology support is available } \\
\text { to you? (Click all that apply.) } \\
\text {-An in-school technology coordinator (for } \\
\text { instructional support) }\end{array}$ & $17-18$ & $\begin{array}{l}\text { Checklist (click all } \\
\text { that apply) }\end{array}$ \\
\hline Availability of technology & $\begin{array}{l}\text { What types of technology are available to you } \\
\text { at school? (Click all that apply.) } \\
\text {-Internet connected computer(s) in my } \\
\text { classroom }\end{array}$ & $15-16$ & $\begin{array}{l}\text { Checklist (click all } \\
\text { that apply) }\end{array}$ \\
\hline Demographics & How many years have you been a teacher? & $22-30,38-41$ & Yes/no, open ended \\
\hline Professional development & $\begin{array}{l}\text { Do you feel that you have received adequate } \\
\text { professional development on the integration } \\
\text { of digital technology into your reading } \\
\text { curriculum? }\end{array}$ & $31-32,34-35,36$ & Yes/no \\
\hline Perceptions about integration & $\begin{array}{l}\text { What do you feel would help you increase } \\
\text { your integration of technology into your } \\
\text { literacy/language arts instruction? }\end{array}$ & 11,21 & Open ended \\
\hline
\end{tabular}

examples of the categories of ICTs identified in several of the items. The final version of the survey consisted of 69 items with responses on a Likert scale, 11 multiple choice items, and eight open-ended items, for a total of 88 items. (The survey can be examined at www.surveymonkey.com/s/KJJDQ6F.) Table 2 summarizes the major constructs in the final survey, followed by a sample item, the corresponding item numbers on the survey, and the format of responses for each construct.

For several of these constructs, response formats that produced only numerical responses-as opposed to, for example, open-ended statements-allowed us to create composite scales (a term preferred in survey research rather than "composite scores"). These scales, highlighted with an ${ }^{\mathrm{a}}$ in Table 2, were used in an exploratory factor analysis and a path analysis, as detailed later in this article.

\section{Disseminating the Survey and Soliciting Participation}

To decrease errors due to inadequate coverage, sampling, and nonresponse, the dissemination of the survey and the solicitation of participation were guided by what Dillman, Smyth, and Christian (2009) referred to as tailored design, which is advocated by Baumann and Bason (2011) in the area of literacy research. Thus, during three months the full survey was distributed in several stages through multiple contacts. Each subsequent contact was intended to increase motivation and investment in completing the survey diligently and fully. Research has suggested that such multiple contacts and opportunities to complete the survey effectively improve the response rates (Schaefer \& Dillman, 1998). 
The initial contact consisted of sending a personal e-mail to each of the presidents and membership chairs of all the state IRA councils to inform them of the study, to request their cooperation in facilitating the study, and if they consented, to make them aware that they would subsequently receive further instructions about how they could participate. That e-mail also pointed out the importance of gathering such data to address IRA's goals. In addition, it informed the state presidents and membership chairs that if at least $15 \%$ of their members completed the survey, they would receive a customized report of the survey findings for their state. Five days after the first e-mail, a second e-mail contact was made with state presidents and membership chairs. The second e-mail suggested several ways each state president or membership chair could invite their state reading association members to complete the survey, and it included a sample invitation e-mail. They were asked to send the invitation e-mail to their members through their e-mail distribution list, or to inform the researcher if an e-mail invitation was not possible. Based on Grawford, Couper, and Lamias's (2001) finding that a single e-mailed reminder doubled the number of responses, approximately a week after the second contact, a reminder was e-mailed to presidents who had not replied.

Twenty-three state presidents or membership chairs $(47 \%$ of all presidents and chairs) did not respond to either the first or second e-mail. Four state presidents $(<1 \%)$ declined to participate because they did not have an e-mail list or because of concerns about members' privacy. In these cases, an e-mail was sent with other options for announcing the survey and distributing the survey link, including posting a link to the survey to the organization's webpage and announcing the survey in a state newsletter. After determining which state reading associations declined participation, we e-mailed personal contacts in those states to request suggestions about how to distribute the survey effectively to the appropriate population and who might be contacted to facilitate dissemination through e-mail. These contacts led to participation in five additional states. The survey was available online from January 2009 through March 2009.

\section{Sampling and Rates of Response}

Although online surveys have many advantages and are increasingly viewed as a useful and necessary tool among survey researchers (Dillman et al., 2009; Sue \& Ritter, 2007), they also pose unique methodological challenges when compared with traditional methods. Although these challenges suggest caution in interpreting results, they do not negate the usefulness and validity of results under certain conditions. For example, as
Dillman (2007) noted, online surveys are particularly appropriate for surveying "certain populations, such as university professors, federal government employees, workers in many companies and corporations, and members of some professional organizations" (p. 356), who generally have Internet access. In that regard, there is reason to believe that virtually all literacy teachers have access to the Internet. For example, in 2005 the Pew Internet \& American Life Project survey found that $85 \%$ of college graduates regularly accessed the Internet (Raine \& Horrigan, 2005).

It is not possible to specify a response rate because the number of individuals who received an invitation to participate is unknown. For example, in several cases the survey link was posted to an organizational website or in a newsletter. Nonetheless, we believe that the relatively high number of respondents, which would produce a relatively small sampling error $(<3 \%$ at a $95 \%$ confidence level) if it were a true random sample, compensates somewhat for this limitation, as argued by Sue and Ritter (2007). Further, the total number of members of the IRA state affiliates is approximately 75,000 (Anne Fullerton, personal communication, March 17, 2010). Thus, the number of respondents was approximately $2 \%$ of the total subpopulation, and there was no reason to believe that any members of state affiliates were systematically excluded on the basis of factors related to the present investigation. Further, as noted in a previous section, respondents represented a diversity of demographic variables such as age, teaching experience, grade level taught, and region of the United States, and they were proportionately consistent in most cases with the overall membership of the IRA.

\section{Preliminary Data Analysis}

Analysis began by deleting any surveys that were less than $85 \%$ complete. The number of returned surveys was 1,637 , and $196(11 \%)$ were omitted due to inadequate completion, resulting in 1,441 useable surveys. Any remaining missing data were handled using the data analysis software SPSS (SPSS, 2010) and Mplus (Muthén \& Muthén, 2007). In computing the descriptive statistics, missing data were handled using pairwise deletion in SPSS. For the path model, missing data were handled using maximum likelihood estimation in Mplus. These methods were selected after the missing data patterns were examined using the analysis command in Mplus and it was determined that the data were missing at random (MAR).

\section{Exploratory Factor Analysis}

Maximum likelihood exploratory factor analysis was conducted to examine the internal reliability of the survey and identify the underlying factor structure 
suggested by the pattern of responses. Items pertaining to demographic characteristics, open-ended items, and checklist items for which respondents only checked a box to indicate if something was available to them were not included in the factor analysis. First, the factorability of the items was examined. Assumptions for factorability of the data were sufficiently met based on Bartlett's test of sphericity, the Kaiser-Meyer-Olkin measure of sampling adequacy, and the correlation matrices. A Promax solution for rotation was selected because the items within each of the variables were likely to be related. Three items were eliminated because they loaded below the acceptable level of 0.30 . A five factor solution was selected by examining (a) eigenvalues greater than 1.0, (b) the scree plot of eigenvalues, (c) factor loadings greater than 0.30 , and (d) substantive interpretability of the factor structures. Internal consistency for each of the factors was examined using Cronbach's $\alpha$. Factor solutions are reported in Table 3.

\section{Hypothesized Path Model}

The constructs in the survey, including factors determined through the exploratory factor analysis, were used to develop a hypothesized path model. The model was derived from the existing theoretical and empirical literature (reviewed previously in this article) specifically the consistent finding that beliefs about the importance of integrating technology into instruction were related to the extent of integration (e.g., Angers \& Machtmes, 2005; Ertmer \& Ottenbreit-Leftwich, 2010; Hermans, Tondeur, van Braak, \& Valcke, 2008; Windschitl \& Sahl, 2002). Thus, in our model we hypothesized a direct path between perceived importance of ICTs (the summed raw scores from the perceived importance factor, items $5 \mathrm{~A}-\mathrm{K}$ and $6 \mathrm{~L}-$ $\mathrm{R}$ ) and the reported extent of integration (the summed raw scores from the extent of integration factor, items $3 \mathrm{~A}-\mathrm{K}$ and $4 \mathrm{~L}-\mathrm{R})$. Additional factors were included in the model as potential mediating variables. Specifically, variables labeled as professional development (PD) skill (item 31 in the survey) and as $P D$ integration (item 32 in the survey), and the competency factor (the summed raw scores from the competency factor, items 7-9) were included based on Zhao et al.'s (2002) report on the importance of teachers' skill and pedagogical understandings regarding technology integration. The variables labeled as stance (created from the summed standardized scores from the stance factor; items 10, 20, and 37), availability (the summed raw scores from items 15 and 16) and support (the summed raw scores from items 17 and 18) were added based on Christensen and Knezek's (2002) Will, Skill, Tool model. This model emphasized the effect of attitudes toward ICTs and the
Table 3. Factor Loadings

\begin{tabular}{lcccc}
\hline Factor & $\begin{array}{c}\text { Item } \\
\text { loadings }\end{array}$ & $\begin{array}{c}\text { Number } \\
\text { of items }\end{array}$ & $\begin{array}{c}\text { Cronbach's } \\
\alpha\end{array}$ & $\begin{array}{c}\text { \% common } \\
\text { variance }\end{array}$ \\
\hline $\begin{array}{l}\text { Extent of } \\
\text { integration }\end{array}$ & $.38-.87$ & 18 & .92 & 52.84 \\
$\begin{array}{l}\text { Perceived } \\
\text { importance }\end{array}$ & $.57-.86$ & 18 & .94 & 57.21 \\
Obstacles & $.38-.70$ & 22 & .89 & 30.62 \\
Competency & $.76-.90$ & 3 & .80 & 72.02 \\
Stance & $.73-.80$ & 3 & .66 & 59.73 \\
\hline
\end{tabular}

Figure 1. Hypothesized Path Model of Factors Related to the Extent of Integration of ICTs

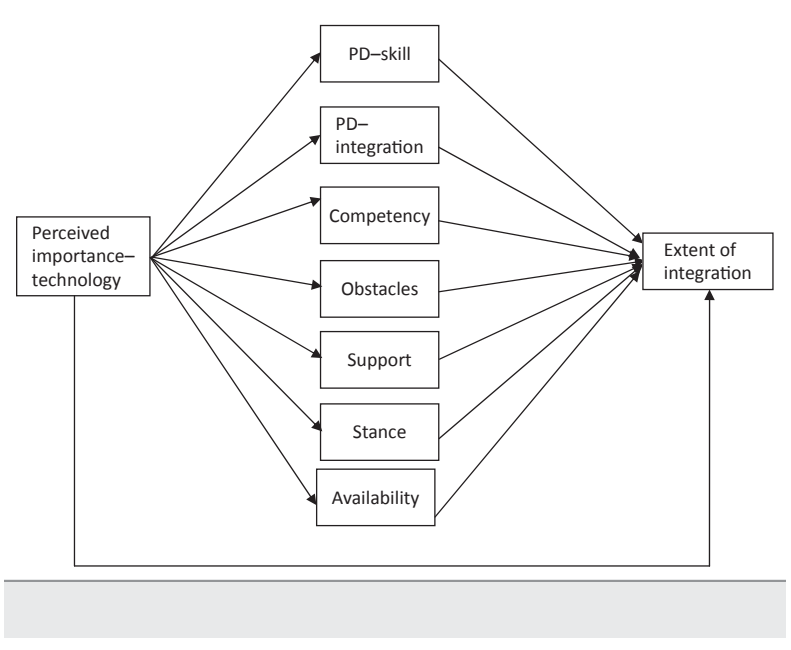

availability of ICTs and relevant resources on ICT integration. Finally, we included a variable based on the summed values of responses to the items on the obstacles composite scale. This variable represents the range of obstacles displayed in Table 8 as derived from our review of the literature. The hypothesized model is displayed in Figure 1.

To conduct the path analysis, the composite scales became variables in the path analysis by summing the raw scores of the items included in each variable, with the exception of the variable labeled stance. Instead, Z scores were summed to create this variable because the items comprising that variable did not include identical response scales.

\section{Results}

In this section, we present results in subsections corresponding respectively to the six research questions outlined in the beginning of this article. 


\section{Are Relevant Technologies and Technical Support Available?}

Because literacy teachers cannot be expected to integrate ICTs fully into instruction if they lack requisite technological tools and support, our first research question addressed teachers' perceptions of the extent to which relevant technologies and technological support were available for their instruction. On the survey, literacy teachers identified which of several technologies related to ICTs were available for their instruction

Table 4. Percentage of Teachers Reporting Availability of Relevant Technologies for Literacy Instruction

\begin{tabular}{lc}
\hline Technological capability & $\begin{array}{c}\text { Teachers reporting } \\
\text { availability } \%(n)\end{array}$ \\
\hline $\begin{array}{l}\text { Computer(s) connected to the Internet } \\
\text { in school (outside of classroom) }\end{array}$ & $92.0(1,325)$ \\
$\begin{array}{l}\text { Computer(s) connected to the Internet } \\
\text { (in classroom) }\end{array}$ & $86.1(1,240)$ \\
Digital projector & $66.7(961)$ \\
Interactive whiteboard & $43.1(621)$ \\
Laptop computer(s) at school for personal use & $41.1(592)$ \\
Digital video recording equipment & $32.0(461)$ \\
Document camera & $15.3(220)$ \\
Laptop computers for each student & $12.3(177)$ \\
Student e-mail & $11.4(164)$ \\
Personal Data Assistant (PDA) & $7.0(101)$ \\
iPod & $5.8(83)$ \\
\hline
\end{tabular}

Table 5. Percentage of Teachers Reporting Availability of Technical Support for Using ICTs

\begin{tabular}{lc}
\hline Type of support & $\begin{array}{c}\text { Teachers reporting } \\
\text { availability \% }(n)\end{array}$ \\
\hline $\begin{array}{l}\text { District technology coordinator (for technical } \\
\text { support) }\end{array}$ & $73.8(1,063)$ \\
Library/media specialist & $70.5(1,015)$ \\
Another teacher who assists with technology & $48.0(691)$ \\
$\begin{array}{l}\text { In-school technology coordinator (for } \\
\text { technical support) }\end{array}$ & $47.4(683)$ \\
$\begin{array}{l}\text { Administrative support (for obtaining resources, } \\
\text { PD, etc.) }\end{array}$ & $46.7(673)$ \\
$\begin{array}{l}\text { District technology coordinator (for } \\
\text { instructional support) }\end{array}$ & $46.2(665)$ \\
$\begin{array}{l}\text { In-school technology coordinator (for } \\
\text { instructional support) }\end{array}$ & $31.9(459)$ \\
No assistance provided & $1.6(23)$ \\
\hline
\end{tabular}

and what types of support were available for using them. The technologies listed in the survey included those necessary to engage in using ICTs (e.g., Internet connections), those that would facilitate use and integration of ICTs into instruction (e.g., digital projectors and interactive whiteboards), and those that might fit into both of these areas (e.g., laptops for individual students). Tables 4 and 5 respectively summarize the results, in descending order, for availability of the specified technologies and types of support. These data indicate that although access to the Internet, which is a fundamental capability to using ICTs, is widespread, one third of the teachers reported that they do not have access to a digital projector. Fewer than half of the teachers reported having access to several other useful tools and capabilities that would facilitate integrating ICTs into literacy instruction. For example, fewer than 1 in 8 teachers reported that laptops were available for each student to use during instruction. Although Internet access is ubiquitous, many literacy teachers reported that they lack these two important tools necessary for integrating ICTs into large-group or whole class instruction. Virtually all teachers reported some form of technical support, most often at the district level, with only $1.6 \%$ reporting no assistance.

\section{What ICTs Are Perceived as Important, and How Often Are They Being Used?}

To address our second research question, we asked literacy teachers to indicate the extent to which they engage their students in activities involving specific ICTs. The activities listed in that section of the survey included those identified in the literature as examples of new literacies (Leu et al., 2004), 21st-century literacy (International Reading Association., 2009), and the skills and strategies associated with online reading comprehension (Leu et al., 2007). We reasoned that these activities would reflect curricular rather than simply technological integration (e.g., using presentation tools). We also reasoned that there might be a relation between reported frequency and perceptions of importance. Thus, using the identical Likert scale for responses, we asked teachers to identify the importance of integrating the same ICTs into instruction. Table 6 compares respondents' reported frequency and their rated importance of using each of the ICTs included in the survey. Means and standard deviations in the table were computed from responses on a Likert scale, which were assigned values as follows: not at all (0), a small extent (1), a moderate extent (2), and a large extent (3). The activities are listed in descending order of reported frequency from those reported being used most frequently to least frequently, paired with the rated importance for each activity respectively. The third column indicates the difference between the 
Table 6. Means and Standard Deviations of Reported Frequency and Importance of Using ICTs in Instructional Activities

\begin{tabular}{|c|c|c|c|}
\hline Instructional activity using ICTs & $\begin{array}{l}\text { Reported } \\
\text { frequency } \\
M(S D)^{\mathrm{a}}\end{array}$ & $\begin{array}{l}\text { Perception of } \\
\text { importance } \\
M(S D)^{\mathrm{a}}\end{array}$ & $\begin{array}{c}\text { Difference between } \\
M \text { frequency and } \\
M \text { importance }\end{array}$ \\
\hline Creating a Word document & $2.69(1.22)$ & $3.36(0.89)$ & -0.67 \\
\hline Locating information online & $1.57(1.07)$ & $2.45(0.83)$ & -0.88 \\
\hline Searching for information online (without specific search strategies) & $1.56(1.10)$ & $2.43(0.85)$ & -0.87 \\
\hline Using reference sites online & $1.46(1.09)$ & $2.28(0.92)$ & -0.82 \\
\hline Playing educational games online & $1.37(1.05)$ & $1.38(1.05)$ & -0.01 \\
\hline Gathering pictures online & $1.25(0.99)$ & $1.79(0.92)$ & -0.54 \\
\hline Searching for information online (with specific search strategies) & $1.19(1.07)$ & $2.32(0.95)$ & -1.13 \\
\hline Reading a story online & $1.15(1.01)$ & $2.06(0.88)$ & -0.91 \\
\hline Creating a multimedia presentation & $1.13(1.09)$ & $2.08(1.02)$ & -0.95 \\
\hline Playing educational games on CD-ROM & $1.07(1.05)$ & $1.61(.94)$ & -0.54 \\
\hline Evaluating information online & $1.03(1.04)$ & $2.24(0.99)$ & -1.21 \\
\hline Synthesizing information online & $0.96(1.02)$ & $2.14(1.03)$ & -1.18 \\
\hline Formulating questions to research online & $0.91(0.99)$ & $2.08(1.01)$ & -1.17 \\
\hline Sending e-mail & $0.47(0.88)$ & $1.28(1.07)$ & -0.81 \\
\hline Publishing information on a website & $0.32(0.70)$ & $1.29(1.05)$ & -0.97 \\
\hline Publishing information on a wiki or blog & $0.26(0.66)$ & $1.18(1.06)$ & -0.93 \\
\hline Collaborating online with students from other classes & $0.24(0.59)$ & $1.63(1.02)$ & -1.39 \\
\hline Communicating using Instant Messenger or other chat tools & $0.17(0.56)$ & $0.80(0.94)$ & -0.63 \\
\hline
\end{tabular}

${ }^{a}$ Means and standard deviations for frequency and importance computed from responses on the following scale: not at all (0), a small extent ( 1 ), a moderate extent (2), and a large extent (3).

mean values for frequency and importance for each activity.

Comparing frequency and importance in Table 6 reveals several potentially insightful patterns. First, for each activity listed, subtracting the mean for rated importance from the mean for reported use results in a negative value. Thus, in every instance, respondents rated the importance as greater than the frequency of use (with the caveat that the items on frequency and importance are not necessarily isomorphic, despite using identical scales). Among the literacy teachers responding to this survey, there seemed to be a gap between their perceptions about the importance of integrating ICTs into their instruction and their reported use of them. A second pattern is that for some items, there is a relatively close connection between the teachers' beliefs about importance and the frequency of use on the lower end of each Likert scale. For example, for communicating using Instant Messenger or other chat tools, the means for frequency (0.17) and for importance $(0.80)$ are both relatively low, indicating a relatively close connection between low-rated importance and reported use. A similarly close connection between lower rated importance and reported use is evident for other new genres of reading and writing, such as publishing information on a wiki or blog, publishing information on a website, and even sending e-mail. Finally, Table 6 also shows that the larger differences between reported frequency of use and rated importance are between uses associated with the 21stcentury skills for literacy that imply curricular rather than technological integration (i.e., collaborating online with students from other classes, evaluating information online, synthesizing information online, formulat- ing questions to research online, searching for information online, and, to an extent, reading a story online).

\section{How Do Teachers Conceptualize and Define Integration?}

Our third research question addressed how literacy teachers conceptualize and define integrating ICTs into instruction. To address that question, teachers were asked to respond to the following open-ended question: "What do you think it looks like to integrate technology into literacy instruction? Give as many ideas as you can." Five scrolling text boxes were provided for responses. All respondents entered a response in at least one text box, and the majority entered a response in all five boxes. Less than 1\% of the respondents indicated that they did not know what integration of ICTs meant.

Responses were analyzed using a content analysis approach (Neuendorf, 2002) with an emergent coding scheme. First, two researchers independently reviewed all of the responses, each creating an initial list of categories into which the responses seemed to fit. Then they met to discuss their independent categories, creating a set of common codes. For example, at this stage they decided that all responses related to using ICTs for multimedia presentations, to showing documents using a document camera, to using digital projectors, or to presenting information to a group would be coded as presentation tools. Using these codes, the researchers each independently coded the same 150 randomly selected responses. They met again to compare their coding and agreed that three 
Table 7. Conceptualizations and Definitions of ICT Integration: Codes and Percentage of Teachers' Responses for Each Code

\begin{tabular}{|c|c|c|}
\hline Code & Description & $\begin{array}{l}\% \text { of respondents } \\
\text { coded accordingly }\end{array}$ \\
\hline Presentation tools & $\begin{array}{l}\text { Using ICTs (students or teachers) for presenting information (e.g., making } \\
\text { multimedia presentations or demonstrations, displaying websites and other } \\
\text { information, using document cameras) }\end{array}$ & 38 \\
\hline Research & Students using ICTs for research on any topic & 23 \\
\hline $\begin{array}{l}\text { Supplement or replacement } \\
\text { for existing materials and } \\
\text { instruction }\end{array}$ & $\begin{array}{l}\text { Using ICTs to replace activities that were already being conducted with } \\
\text { conventional materials (e.g., Word documents), or to supplement, extend, or } \\
\text { support existing instructional content or activities (e.g., using an interactive } \\
\text { whiteboard to do word sorts) }\end{array}$ & 20 \\
\hline $\begin{array}{l}\text { Enhancement tool and building } \\
\text { block for background } \\
\text { information }\end{array}$ & $\begin{array}{l}\text { Using ICTs for building background knowledge prior to reading instruction, and } \\
\text { for extending and enhancing reading instruction and reading topics }\end{array}$ & 16 \\
\hline Computer as tutor & $\begin{array}{l}\text { Using ICTs to provide supplemental instruction or to reinforce instruction } \\
\text { (e.g., online tutorials and educational games) }\end{array}$ & 15 \\
\hline Computer as publisher & $\begin{array}{l}\text { Using ICTs for publishing students' work online (e.g., on blogs or websites, or in } \\
\text { podcasts) and offline (e.g., word processing to print stories and assignments) }\end{array}$ & 15 \\
\hline Student interaction & $\begin{array}{l}\text { Using ICTs to allow students to interact with the teacher during instruction } \\
\text { (e.g., students use clickers to provide responses), and to allow for interactive } \\
\text { work between students (e.g., students share an online writing space) }\end{array}$ & 14 \\
\hline $\begin{array}{l}\text { Alternative format reading } \\
\text { and texts }\end{array}$ & $\begin{array}{l}\text { Using ICTs for reading in formats other than conventional print (e.g., e-books, } \\
\text { audio-supported readings, blogs, and books on iPods) }\end{array}$ & 13 \\
\hline $\begin{array}{l}\text { Enhancing the instructional } \\
\text { environment }\end{array}$ & $\begin{array}{l}\text { Using ICTs to enhance the instructional environment to improve students' interest, } \\
\text { engagement, excitement, comfort, sense of challenge, and inspiration to learn }\end{array}$ & 12 \\
\hline Writing & $\begin{array}{l}\text { Using ICTs (students and teachers) for conventional writing, digital story writing, } \\
\text { interactive writing, creating photo stories, editing and revising, learning the } \\
\text { writing process, and as a tool for writing to real audiences }\end{array}$ & 12 \\
\hline
\end{tabular}

new codes were needed. Using the additional three codes, the researchers scored an additional 150 responses and compared their coding. No new codes emerged, and intercoder agreement was 96\%. Considering this acceptable agreement, the researchers divided the remaining responses and coded them independently.

Table 7 summarizes the codes, a description of each code, and the percentage of teachers whose responses related to each code. Codes are listed in descending order by percentage, and only those codes that captured at least 10\% of the teachers' responses are listed.

These results suggest that many literacy teachers conceptualize integration primarily as technological rather than curricular. That is, they see integration more often as enhancing conventional instructional goals or using technology for its own sake as opposed to adopting new instructional goals involving new activities. Consistent with this interpretation, despite the fact that literacy teachers acknowledge the importance of skills, strategies, and dispositions associated with 21st-century literacy, they do not identify such uses of ICTs as central to their conceptions of integration. For example, in Table 6, creating word processing documents and searching for information online were among the few functions that teachers indicated they used at least moderately and that suggest curricular integration, although these uses also lend themselves readily to supplementing more conventional instruction. Likewise, a relatively high percentage of teachers identified more perfunctory activities, such as using computers as presentation tools (38\% of responses, which was the most consistent response) and as a supplement to existing instruction (20\% of responses), as consistent with their conception of integrating ICTs into their instruction. Similarly, among the themes that less than $10 \%$ of the teachers identified as consistent with their conceptualization of integration were those associated with curricular integration, such as authentic activities aimed at preparing students for adulthood in the 21st century $(2 \%)$ and an awareness of global communication for global understandings (2\%).

\section{What Is the Perceived Role or Benefit of Technology?}

To further study literacy teachers' beliefs, our fourth research question addressed their perceptions about the role and benefit of ICTs. Respondents were 
asked to choose from among the following statements the one that is closest to their own view (each followed by the percentage of respondents selecting that statement): (1) "Technology should not be used in instruction" $(0.06 \%)$, (2) "Technology is not important to instruction" (1\%), (3) "Technology is supplemental to instruction" (67\%), (4) "Technology is central to instruction" (29\%), and (5)" I don't know" (2.4\%). When they were asked to indicate the extent to which technology benefits instruction, most indicated that its benefits were large $(46 \%)$ or moderate $(40 \%)$. Less than $1 \%$ selected "not at all" and $5 \%$ were unsure. These data suggest that virtually all literacy teachers believe that technology should be integrated into instruction, but two thirds indicated that it played a supplemental role. Likewise, a substantial majority $(86 \%)$ believed that its benefits were large or moderate.

\section{What Are Perceived Obstacles to Integration?}

A fifth research question addressed literacy teachers' perceived obstacles to integrating ICTs into instruction. For the present study, we drew on and extended an earlier analysis of the survey data pertaining to this question (Hutchison \& Reinking, 2010). Knowing what literacy teachers perceive to be obstacles to integrating ICTs may be informative, for example, in (a) planning professional development, (b) developing educational policy, and (c) as a benchmark for monitoring ICT integration in the future. Perceived obstacles to integration was also a variable included in the model generated from the exploratory factor analysis described in the method section, and in a statistical test of the model described in the subsequent section.

Teachers indicated their perceptions about obstacles by responding to the following statement: "Please indicate the extent to which you believe the following are obstacles to integrating technology into your literacy/language arts instruction." A list of 21 possible obstacles followed, including 17 drawn from the existing literature and 5 from our experience in working with teachers on projects aimed at integrating ICTs into instruction. These latter items, which participants in the focus group also endorsed, were (a) lack of understanding about how to integrate technology into instruction, (b) lack of professional development related to integrating technology into instruction, (c) lack of understanding about how to evaluate students' ability to use ICTs, (d) Internet texts being too difficult for students to read, and (e) lack of time due to highstakes testing. Possible choices for each potential obstacle were on a Likert scale and were assigned values as follows: not at all (0), a small extent (1), a moderate extent (2), and a large extent (3).
Table 8. Means and Standard Deviations of Responses Concerning Perceived Obstacles to Integrating ICTs Into Literacy Instruction

\begin{tabular}{|c|c|c|}
\hline Potential obstacle & $M^{\mathrm{a}}$ & $S D^{\mathrm{a}}$ \\
\hline Lack of time during a class period & 1.85 & 1.06 \\
\hline Lack of access to technology & 1.73 & 1.13 \\
\hline $\begin{array}{l}\text { Lack of professional development on how to } \\
\text { integrate technology } b\end{array}$ & 1.63 & 1.08 \\
\hline Lack of technical support & 1.58 & 1.1 \\
\hline Lack of time to prepare for using technology & 1.46 & 1.10 \\
\hline $\begin{array}{l}\text { Lack of time to teach students the basic } \\
\text { computer skills needed for more complex } \\
\text { tasks }\end{array}$ & 1.35 & 1.10 \\
\hline $\begin{array}{l}\text { Lack of time to integrate technology because } \\
\text { of the amount of time required to prepare } \\
\text { students for high stakes testing }\end{array}$ & 1.29 & 1.13 \\
\hline Lack of incentives to use technology & 1.01 & 1.02 \\
\hline $\begin{array}{l}\text { Not knowing how to evaluate or assess } \\
\text { students when they work online }{ }^{b}\end{array}$ & 0.93 & 0.89 \\
\hline $\begin{array}{l}\text { Difficulty controlling what information } \\
\text { students access online }\end{array}$ & 0.92 & 0.9 \\
\hline Lack of support from administrators & 0.90 & 1.04 \\
\hline $\begin{array}{l}\text { Not knowing how to incorporate technology } \\
\text { and still teach content standards }\end{array}$ & 0.89 & 0.92 \\
\hline $\begin{array}{l}\text { Internet text seemingly too difficult for } \\
\text { students to read }^{\text {b }}\end{array}$ & 0.87 & 0.91 \\
\hline $\begin{array}{l}\text { Lack of understanding of how to integrate } \\
\text { technology into literacy instruction }\end{array}$ & 0.83 & 0.8 \\
\hline $\begin{array}{l}\text { Not knowing how skilled students are at } \\
\text { using technology }\end{array}$ & 0.82 & 0.87 \\
\hline Considering technology to be unreliable & 0.74 & 0.82 \\
\hline Not knowing how to use technology & 0.65 & 0.8 \\
\hline Lack of understanding of copyright issues & 0.62 & 0.78 \\
\hline $\begin{array}{l}\text { Difficulty managing the classroom when } \\
\text { students are working on computers }\end{array}$ & 0.52 & 0.77 \\
\hline $\begin{array}{l}\text { Thinking that technology doesn't fit my } \\
\text { beliefs about learning }\end{array}$ & 0.29 & 0.6 \\
\hline $\begin{array}{l}\text { Thinking that technology integration isn't } \\
\text { useful }\end{array}$ & 0.17 & 0. \\
\hline
\end{tabular}

aMeans and standard deviations computed from responses on the following scale: not at all (0), a small extent (1), a moderate extent (2), and a large extent (3).

${ }^{\mathrm{b}} \mathrm{An}$ obstacle not reported previously in the literature.

Table 8 presents the obstacles included in the survey with means and standard deviations for the responses to each potential obstacle in descending order with a higher mean representing teachers' perceptions that it was a greater obstacle than one with a lower mean. Thus, the obstacles toward the top of the table are those that are perceived to be more problematic than those toward the bottom of the table.

For 13 of the 21 potential obstacles, the mean value was less than 1.00, a point on the scale representing the 
Table 9. Intercorrelations and Other Descriptive Statistics for Variables in Path Analysis

\begin{tabular}{|c|c|c|c|c|c|c|c|c|c|c|c|c|c|}
\hline Variable & M & $S D$ & $\begin{array}{l}\text { Poss. } \\
\text { range }\end{array}$ & $\begin{array}{l}\text { Sample } \\
\text { range }\end{array}$ & 1 & 2 & 3 & 4 & 5 & 6 & 7 & 8 & 9 \\
\hline Importance & 51.90 & 11.55 & $0-72$ & $18-72$ & - & -.04 & .00 & $.28^{* *}$ & $-.07 *$ & .05 & $.56^{* *}$ & $.14^{* *}$ & $.53^{* *}$ \\
\hline PD_skill & 0.42 & 0.49 & $0-1$ & $0-1$ & - & $.51^{* *}$ & $.33^{* *}$ & $-.38^{* *}$ & $.32^{* *}$ & .00 & $.22^{* *}$ & $.09^{* *}$ & $.09^{* *}$ \\
\hline PD_-integration & 0.81 & 0.39 & $0-1$ & $0-1$ & - & - & $-.37^{* *}$ & $.38^{* *}$ & $.25^{* *}$ & -.04 & $-.23^{* *}$ & $-.16^{* *}$ & $-.16^{* *}$ \\
\hline Competency & 11.56 & 2.53 & $0-16$ & $4-16$ & - & - & - & $-.47^{* *}$ & $.12^{* *}$ & $.36^{* *}$ & $.25^{* *}$ & $.43^{* *}$ & $.43^{* *}$ \\
\hline Obstacles & 23.07 & 11.37 & $0-66$ & $0-66$ & - & - & - & - & $-.22^{* *}$ & $-.15^{* *}$ & $-.24^{* *}$ & $-.25^{* *}$ & $-.25^{* *}$ \\
\hline Support & 3.65 & 1.73 & $0-7$ & $0-7$ & - & - & - & - & - & $.08^{* *}$ & $.38^{* *}$ & $.12^{* *}$ & $.12^{* *}$ \\
\hline Stance & 6.72 & 1.28 & $0-8$ & $2-8$ & - & - & - & - & - & - & $.16^{* *}$ & $.45^{* *}$ & $.45^{* *}$ \\
\hline Availability & 4.80 & 1.91 & $0-12$ & $0-11$ & - & - & - & - & - & - & - & $.30^{* *}$ & $.30^{* *}$ \\
\hline Level of integration & 35.71 & 11.17 & $0-72$ & $18-72$ & - & - & - & - & - & - & - & - & - \\
\hline
\end{tabular}

perception that the potential obstacle was an obstacle to a small extent. That finding is encouraging and may suggest progress in light of previous findings. However, the mean for 8 of the potential obstacles was greater than 1.00, representing the overall perception that each obstacle was an obstacle to a greater extent. Of those 8 items, the following have been identified as obstacles in the existing literature:

- Lack of time within a class period (Bauer \& Kenton, 2005)

- Lack of access to technology (Bauer \& Kenton, 2005; Honan, 2008; Stolle, 2008; Zhao et al., 2002)

- Lack of technical support (Bauer \& Kenton, 2005; Ertmer et al., 1999; Stolle, 2008; Zhao et al., 2002)

- Lack of time to plan for integrating ICTs into instruction (Ertmer et al., 1999)

- Lack of time to teach basic computing skills (Bauer \& Kenton, 2005; Warschauer et al., 2004)

- Lack of incentives to integrate technology (Zhao et al., 2002)

In addition, two obstacles not identified in the previous literature had mean values greater than 1.00: lack of professional development on how to integrate technology $(M=1.63)$ and lack of time to integrate ICTs because of high stakes testing $(M=1.29)$.

\section{What Factors Predict Teachers' Reported Integration of ICTs?}

Our sixth research question led us to investigate what constructs in the survey predicted teachers' levels of reported use of ICTs. To address that question, we tested the hypothesized path model illustrated and explained in the previous section, describing our exploratory factor analyses. The model included factors derived from the existing literature and reflected in the main constructs that guided the development of the survey. The outcome variable was the composite scale representing extent of integration. The exogenous variable was the perceived importance composite scale. To begin our analysis, bivariate correlations were conducted to test the strength and direction of the relationships among the variables (see Table 9). Because the strength and direction of the correlations were as expected based on our hypothesized model, we continued with the path analysis using Mplus 5.2 (Muthén \& Muthén, 2007) software. The results are shown in Figure 2. We chose to report the paths that were not statistically significant in the model (indicated by a dotted line) for purposes of comparing how various categories of teacher perceptions relate to the extent of ICT integration. For example, the model indicates that a teacher's stance toward ICTs may be a better

\section{Figure 2. Relationship of Perceived Importance of ICT With Reported Extent of Integration of ICT in Literacy Instruction}

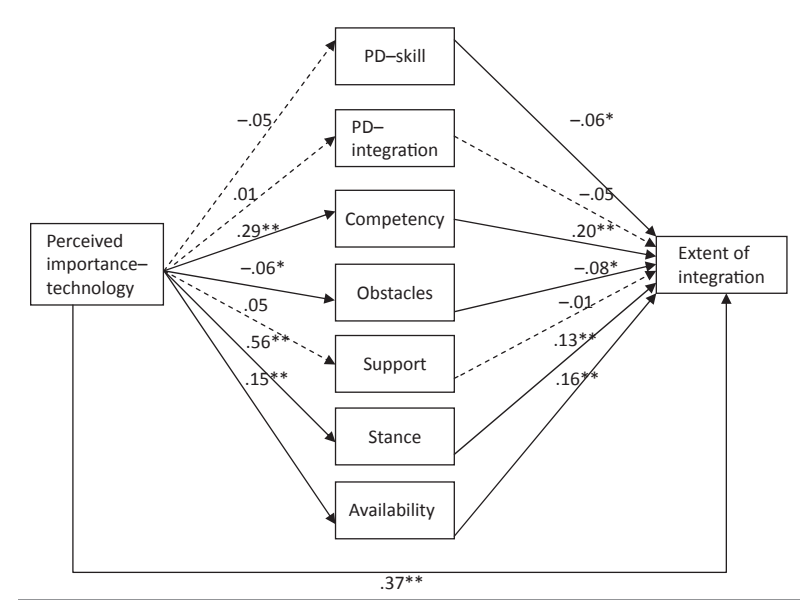

${ }^{*} p<.05, * * p<.01$ 
Table 10. Bootstrap Analysis of Magnitude and Statistical Significance of Indirect Effects

\begin{tabular}{lrrrr} 
Indirect effect & $\begin{array}{c}B \text { (standardized path } \\
\text { coefficient and product) }\end{array}$ & $\begin{array}{c}\text { Mean } \\
\text { indirect effect }\end{array}$ & $\begin{array}{c}\text { SE of } \\
\text { mean }\end{array}$ & $\begin{array}{c}95 \% \text { Cl for mean indirect } \\
\text { effect (Lower, Upper) }\end{array}$ \\
\hline 1. Importance $\rightarrow$ PD-skill $\rightarrow$ level of integration & $-.05 \times-.06=.0030$ & .003 & .002 & $.000, .009^{*}$ \\
2. Importance $\rightarrow$ PD-integration $\rightarrow$ level of integration & $.01 \times .04=.0004$ & .000 & .001 & $-.004, .002$ \\
3. Importance $\rightarrow$ competency $\rightarrow$ level of integration & $.29 \times .20=.0580$ & .058 & .010 & $.041, .080^{*}$ \\
4. Importance $\rightarrow$ obstacles $\rightarrow$ level of integration & $-.06 \times-.09=.0054$ & .005 & .003 & $.001, .012^{*}$ \\
5. Importance $\rightarrow$ support $\rightarrow$ level of integration & $.05 \times-.01=.0005$ & -.001 & .001 & $-.005, .001$ \\
6. Importance $\rightarrow$ stance $\rightarrow$ level of integration & $.56 \times .14=.0784$ & .078 & .013 & $.052, .105^{*}$ \\
7. Importance $\rightarrow$ availability $\rightarrow$ level of integration & $.15 \times .15=.0225$ & .023 & .005 & $.013, .033^{*}$ \\
\hline
\end{tabular}

Note. $n=1,441$

${ }^{*} p<.05$ (excluding zero).

predictor of ICT integration than the amount of support he or she receives.

The bootstrap procedure was used to test the statistical significance of the indirect effects. Bootstrapping was selected because of Mallinckrodt, Abraham, Wei, and Russell's (2006) recommendation that the "use of bootstrap methods provides greater precision when calculating confidence intervals regardless of the sample size, effect size, or level of statistical significance" (p. 377). In general, bootstrapping is an empirical method used to examine the variability of estimates (Efron \& Tibshirani, 1993). In this procedure (see Shrout \& Bolger, 2002), 1,000 bootstrap samples were first created from the original data set by random sampling with replacement. Then the model was tested with these 1,000 samples, yielding 1,000 estimates of each path coefficient. Next, the output from these 1,000 estimates of each path coefficient was used to calculate estimates of indirect effects for the hypotheses. This approach was accomplished by multiplying the 1,000 pairs of path coefficients (a) from perceived importance to each mediator variable (e.g., PD-skill) and (b) from the mediator variable to the outcome variable (extent of integration). If the $95 \%$ confidence interval for the estimates of the indirect effects based on these 1,000 estimates does not include zero, it can be concluded that the indirect effect is statistically significant at the 0.05 level. Table 10 displays the results for the indirect effects, and indicates that five of the seven indirect effects did not include zero and were thus statistically significant.

The resulting model is a linear model with seven mediating variables. Even with seven mediating variables, the standardized direct (or unmediated) effect of teachers' perceptions of the importance of technology on their level of ICT integration for literacy instruction is .37 , which is a moderate effect. $\mathrm{R}^{2}$ for the model- $\mathrm{a}$ measure of the proportion of the variability in teachers' reported use of ICTs explained by the model — was .41 . That is, the model explains $41 \%$ of the variability in teachers' reported use of technology for literacy instruction as determined by the composite scale for the extent of integration, the outcome variable.

Overall, this model suggests that the more teachers perceive IGT use to be important to literacy instruction, the more likely they are to (a) have improved perceptions of their competency with ICTs, (b) improve their stance toward technology and their access to technology, and (c) perceive they have fewer or less severe obstacles to integration. In turn, as competency, stance, and access are perceived to be improved and perceptions of obstacles are reduced, teachers are more likely to report integrating ICTs into their literacy instruction. Of particular note in this model is the fact that professional development on how to integrate ICTs into instruction does not seem related to increasing use of ICTs, and professional development on how to use ICTs is only moderately significant. These findings have implications for the variety and quality of professional development on technology that teachers receive, which we discuss next.

\section{Discussion}

The present study provides a detailed national profile of literacy teachers' perceptions about various aspects of integrating IGTs into literacy instruction. The data reveal perceptions about the extent to which various ICTs are being integrated into literacy instruction and suggest factors that might play a role in efforts to facilitate integration. Thus, this investigation extends and clarifies findings from previous studies, but more importantly it establishes a foundation for future work. We discuss possible interpretations in light of the existing literature, raise questions suggested by the data, and draw tentative conclusions about what our findings suggest for professional development activities, for education policymakers, and for future research. We also highlight limitations that suggest 
caution in drawing unequivocal conclusions, and we suggest avenues for further research.

\section{Availability of Technologies and Technical Support}

A large majority of the literacy teachers completing the survey reported having Internet access in their schools $(98 \%)$ and in their classrooms $(86 \%)$. The level of school access to the Internet is consistent with previous studies for teachers in all subject areas; however, classroom access is somewhat below the 94\% reported by Wells and Lewis (2006) based on data from 2005, and that discrepancy may be somewhat greater at the time of the present study, given the steady upward slope of access since 2000. Thus, although most literacy teachers report having access to the Internet in their classrooms, overall their access may be somewhat less than their peers in other subject areas. In order to promote more integration of ICTs into literacy instruction, administrators may wish to ensure equitable access for literacy teachers. A finer grained analysis, not possible from the present data, would be to determine the ratio of computers available to the students who might use them. Wells and Lewis (2006) reported that, in 2005, the overall national ratio in the United States was one instructional computer to every three students. It may be useful to investigate whether there is a similar ratio within literacy instruction.

Likewise, virtually all of the literacy teachers responding to this survey reported some level of technological support at the district or building level. However, as noted in Table 8, respondents indicated that access to equipment and lack of technical support were predominant obstacles to integration, and these two potential obstacles have been reported often in previous research (Bauer \& Kenton, 2005; Honan, 2008; Stolle, 2008; Zhao et al., 2002). More objective corroborating data may be needed to verify the accuracy of teachers' perceptions. Nonetheless, perceptions are important and suggest that appropriate responses are warranted from administrators, policymakers, and those who conduct professional development.

Despite relatively widespread access to the Internet, our data suggest that many literacy teachers do not have access to useful digital equipment that would facilitate integrating ICTs into instruction. One third of the teachers in this survey reported not having access to a digital projector, and less than half reported having an interactive whiteboard or laptop computers for personal use, which limits options for whole class instruction and may discourage developing instructional activities focused on ICTs. Relatively few teachers (1 in 8) reported having a laptop available for each student. This limitation may be important because individual laptops have been shown in one major study to be a necessary condition for implementing an instructional intervention aimed at explicitly teaching skills, strategies, and dispositions associated with reading comprehension on the Internet (Leu et al., 2009). Thus, one-to-one laptop initiatives may be advisable at the school, district, or state level (e.g., the state of Maine's laptop initiative; see www.maine.gov/mlti/index.shtml). However, making digital technologies and capabilities available to teachers has long been argued to be a necessary but insufficient condition for insuring that activities dependent on those technologies will be assimilated into literacy instruction (e.g., Labbo \& Reinking, 1999; Reinking et al., 2000).

Also noteworthy is the lack of access to, and presumably therefore the lack of use of, e-mail. Less than $12 \%$ of the teachers surveyed reported that their students have access to e-mail at school. That relatively low availability is likely due to concerns about students engaging in inappropriate correspondence and the filters that many schools install to prevent access to inappropriate content on the Internet, which can also complicate the use of e-mail. However, given that e-mail is a ubiquitous component of literacy today that opens up innovative possibilities for collaborative work, (e.g., telecurricular projects; see Craig, 1997), seeking workable solutions to the sociological and technological challenges of arranging for students to use e-mail seems warranted. That conclusion seems especially valid for literacy teachers who would most likely be responsible for helping students acquire necessary skills, strategies, and dispositions related to important new genres of ICTs. Newer social networking applications that have become increasingly popular since we conducted this study further complicate these issues and challenges.

\section{Frequency and Importance of Various ICTs}

Overall, the data on frequency and importance, as summarized in Table 6, suggest that literacy teachers are not integrating ICTs into instruction by engaging in activities typically associated with 21st-century literacy, such as those called for in the IRA and NGTE position statements and standards. Nonetheless, literacy teachers consider these areas to be important. This finding justifies the call for more integration issued by those professional organizations and provides some encouragement for achieving the integration that these professional organizations call for, given that literacy teachers apparently recognize the need for more integration. However, it also raises questions about why such a gap exists and how it might be closed. More research is needed to address the critical issue of how the integration of ICTs into literacy instruction-particularly into 
what we call curricular integration - can be most efficiently and authentically increased without neglecting more conventional and longstanding goals of literacy instruction.

The data from the present investigation provide guidance for such efforts. For example, the data suggest that many teachers do not consider new genres of reading and writing, such as online chats, blogs, wikis, and e-mail, to be important to include in literacy instruction. Taken together, these findings may have implications for engaging literacy teachers in professional development aimed at facilitating integration of ICTs into their instruction. For example, literacy teachers may not need to be convinced that it is important to integrate skills, strategies, and dispositions for online reading into their instruction, but they may be less inclined to integrate new genres of writing unless they can be convinced that engaging students in these genres is useful and important or can contribute directly to accomplishing valued curricular goals, especially those to which they are already committed. Further, it is incumbent on those who advocate for incorporating such ICTs into literacy instruction to justify what conventional or new curricular goals might be accomplished by integrating these genres into instruction.

\section{Conceptualizations, Definitions, Roles, and Benefits of Integrating ICTs Into Instruction}

Teachers' open-ended responses indicated that they conceptualized and defined integration of ICTs into instruction primarily in technological, rather than curricular, terms (see Table 7). Thus, the data suggest, at least indirectly, that relatively few literacy teachers have moved from assimilation of ICTs within their teaching to a deeper curricular accommodation where ICTs are more central to their conceptions of what comprises literacy and literacy instruction (Reinking, Labbo, \& McKenna, 2000). Likewise, when asked about the role of technology in their instruction, two thirds indicated that they see it as supplemental. Yet the present data do not reveal what supplemental means. Does it mean simply an add-on technology to address conventional goals? Or does it mean that new goals related to ICTs supplement more conventional goals? Does their commitment to conventional forms of literacy and traditional standards and content remains strong despite their belief that 21st-century literacies are important, as indicated in their responses in Table 7? What does it mean that almost $30 \%$ of the teachers indicated that ICTs were central to literacy instruction, especially given that high stakes assessments in the United States rarely access aspects of digital literacy (Leu, 2006)? In that regard, it would be enlightening to create a version of this survey for administrators, policymakers, and teacher educators to determine their conceptions of integrating ICTs into literacy instruction. It may be unreasonable to expect teachers to deepen their conceptions of ICT integration without the leadership, encouragement, and assistance of those responsible for supporting the integration of ICTs into instruction through, for example, professional development.

\section{Perceived Obstacles to Integrating ICTs Into Literacy Instruction}

Literacy teachers responding to this survey identified many of the same obstacles to integration of technology into instruction as teachers in other curricular areas, as reported in previous research (see Hutchison \& Reinking, 2010). However, 13 of the 21 potential obstacles were rated on average as an obstacle less than a small extent, suggesting that on the whole, literacy teachers do not perceive the full range of potential obstacles identified previously in the literature to be a major stumbling block to integrating ICTs into instruction. The most prominent obstacle was a lack of time to integrate ICTs during a class period, which suggests indirectly that literacy teachers may see activities involving ICTs as supplemental to conventional instructional goals (i.e., they perceive ICTs to require extra time). Other prominent obstacles included (a) lack of access to technology and technical support, (b) lack of professional development on how to integrate technology (a factor not identified in the previous literature), (c) inadequate time to prepare for lessons involving ICTs, (d) lack of time to teach basic computer skills, (e) the amount of time that must be devoted to high-stakes testing, and (f) a lack of incentives to integrate ICTs.

Most of the more prominent obstacles teachers identified in the survey fall into a category that Ertmer et al. (1999) referred to as extrinsic factors (i.e., factors that are external to teachers and often beyond their control). That finding, if an accurate perception, suggests that administrators and policymakers need to take a more active role in and responsibility for facilitating integration. As suggested by the results pertaining to accessing useful technologies and technical support, where there is a lack of integrating ICTs into literacy instruction, the remedy may not be simply to encourage teachers to increase their integration or to rely solely on professional development. Correspondingly, intrinsic factors such as teachers' beliefs about integrating technology into instruction may not be a major obstacle to integration. Few teachers indicated that their own beliefs about the use of technology and learning and their beliefs about integrating ICTs into instruction were obstacles, even to a small extent 
( $M=0.29$ and $M=0.17$, respectively, on a 3-point scale). These data suggest that a majority of the literacy teachers responding to this survey are open to integrating digital technologies into instruction. However, that conclusion must be tempered by the finding, as noted previously in this discussion, that they also define integration primarily in technological rather than curricular terms. It must also be tempered by the results of the path analysis because it indicated that a more positive stance toward technology is associated with increased use of ICTs for literacy instruction.

\section{Factors Predicting Extent of ICT Integration}

The path analysis clarified and provided more nuanced interpretations of the descriptive data discussed thus far. The model shown in Figure 2 suggests that beliefs about the importance of technology are directly related to levels of integrating ICTs into instruction. Put simply, the more that teachers believed that each of several possible ways of integrating technology into instruction was important, the higher their reported level of integration. That finding suggests that teachers' beliefs about the importance of integrating various ICTs into instruction are critical to increasing levels of integration. As indicated in Figure 2, the relation between beliefs about importance and levels of integration was also achieved through several mediating variables. A teacher's stance toward technology, which is essentially a belief logically related to importance, mediated the strongest indirect effect $(.08 ; p<.001)$ between beliefs about importance and level of integration. Thus, according to the model, if teachers perceived technology as important, they were more likely to have a positive stance toward its use in the classroom and its benefit to students, in which case they were more likely to integrate technology into instruction. Therefore, the path analysis converges with interpretations of the descriptive data from this survey, suggesting that teachers' beliefs and conceptions are strong predictors of the extent to which they reported integrating ICTs into instruction. That conclusion is consistent with much previous research, indicating that teachers' beliefs about technology are foundational to how it is conceptualized and used in their instruction (Bruce \& Rubin, 1993; Clark \& Peterson, 1986; Ertmer, 2005; Windschitl \& Sahl, 2002; Zhao et al., 2002).

Other statistically significant mediating factors in the model included (a) competency, as indicated by teachers' perceptions of their abilities to use ICTs, to teach online reading skills, and to integrate ICTs into instruction; (b) perceptions of fewer obstacles; and (c) availability of technology. These findings suggest that the more importance teachers ascribed to various uses of ICTs, the more their increased integration was mediated by (a) the acquisition of competency, (b) a reduction in the reported obstacles, and (c) by greater access to facilitative technologies. For example, if teachers indicated a relatively strong belief in the importance of technology, they were more likely to (a) view themselves as competent at using and integrating technology, (b) minimize the effects of obstacles, and (c) have or seek out access to necessary technologies. However, determining the precise roles of these factors and how they are related to each other in relation to perceived importance and levels of integration awaits further research. This determination could perhaps be accomplished by using a somewhat modified or more focused version of the present survey. Another option might be to monitor whether approaches aimed at increasing literacy teachers' investment in the importance of integrating ICTs into instruction, if successful, results in concomitant increases in these mediating variables as well as in overall integration. Other methodological approaches such as case studies and interviews might also investigate these relations.

These results lead us to speculate about whether there may be an underlying motivational factor that leads teachers who believe strongly in the importance of integrating technology to seek appropriate professional development and overcome obstacles to integration, including finding necessary equipment (e.g., by writing a grant). If so, then enhancing teachers' perceptions about the importance of integrating ICTs into instruction takes on added importance, although as reported previously in this section, the literacy teachers in the present study typically recognized the importance of 21st-century skills when asked, but they did not spontaneously include them in their definitions of integration. Further research might specifically investigate the relation among beliefs about the importance of integrating ICTs, motivation to do so, and actual integration.

The path analysis also revealed other potential indirect effects of the mediating variables. For example, teachers' perceptions about the adequacy of their professional development on how to use technology were marginally related to levels of integration, and teachers' assessments of the adequacy of their professional development on how to integrate technology into literacy instruction were not statistically related to integration. This finding suggests that the professional development that teachers receive on technology use and integration is not sufficient or appropriately focused. For example, professional development aimed at using new technologies only as isolated tools may actually reinforce teachers' conceptualization of integrating ICTs as technological, rather than curricular, integration. That interpretation is supported by Lawless and Pellegrino's (2007) 
assertion that much of the professional development on technology is "driven by a very strong perceived need for action, but it is often not guided by any substantial knowledge base derived from research about what works and why, with regard to technology, teaching, and learning" (p. 576). Our results reinforce their call for a systematic study of professional development aimed at increasing the integration of digital technologies into instruction. They also suggest the value of alternative approaches to research, which reveal enhancing and inhibiting factors to guide iterative development of promising models of professional development, aimed at increasing curricular integration (see Reinking \& Bradley, 2008).

The analysis of indirect effects noted in the path analysis also complicates an understanding of the role of technological support, as indicated in the descriptive data where more than $80 \%$ of the teachers identified a lack of such support as an obstacle to integration. Although technological support was a mediating factor in the model, it was not singularly the statistically significant factor in relation to reported levels of use. That finding suggests several possible interpretations. For example, technological support may be less of an obstacle than many teachers believe, or teachers may not make use of the support available. Further, teachers who have a strong commitment to the importance of integrating ICTs and who have a positive stance toward technology may also be more motivated to circumvent or resolve technological difficulties on their own. Or perhaps the technological support that virtually all teachers reported as being available, at least at a district level, is not useful or appropriate to teachers' instructional needs. That view was often expressed in responses to the open-ended items. For example, one respondent stated, "Our technology person is not nice and hard to ask questions to. If I have a problem with my technology, I would rather not use it than seek help from the cranky, self-righteous, condescending tech."

Nonetheless, several indirect effects were related to actual integration of ICTs at statistically significant levels. Specifically, (a) a positive stance toward technology, (b) perceived confidence in being able to integrate technology into instruction, and (c) the availability of diverse technologies were all predictors of the extent of integration. Thus, increases in any of these areas may lead to increases in the level of integrating ICTs into instruction, independent of views about the importance of technology. A positive stance toward integrating technology into instruction and confidence in doing so are intrinsic factors (Ertmer et al., 1999) related to teachers' beliefs and perceptions. These findings again suggest the importance of addressing teachers' beliefs and perceptions in any effort to increase the integration of ICTs into literacy instruction. The find- ing that availability also was related statistically to reported use moderates to some extent previous views that making technology available is only a necessary, not sufficient, condition to increasing integration (e.g., Labbo \& Reinking, 1999). Unlike a decade or more ago when the availability of technology meant simply having access to a computer and specific software programs, it is possible that newer, more established digital technologies such as the Internet and interactive whiteboards more readily invite integration of ICTs into instruction; therefore, it is possible that making such technologies available to teachers can substantively enhance integration.

\section{Conclusions and Implications}

Overall, the results of the present study might be framed as the proverbial case of looking at a glass as half full or half empty. For those invested in realizing the goals of integrating 21st-century literacy as identified in the IRA and NGTE position statements and standards, our results suggest cause for both optimism and concern. For example, an absolute majority of the teachers responding to this survey clearly understand and accept that literacy instruction needs to address digital forms of reading and writing, and they acknowledge the importance of doing so, although their perception of frequency of use does not typically coincide with the level of importance they assign to various applications and activities. They are also not likely to consider new forms of digital reading and writing as central to their conception of integrating ICTs into instruction, and perhaps rightfully so as some researchers have questioned whether certain ICTs have a place in the classroom (e.g., Lewis \& Fabos, 2005).

Although the teachers in this study acknowledged many obstacles to integrating ICTs into instruction, they did not see those obstacles as overwhelming or unmanageable. Perhaps contrary to popular assumptions, many of them were also confident in their ability to integrate ICTs into instruction, despite their expressed need for professional development that helped them find ways to do so. Seventy-one percent of the participants indicated that they believed themselves capable of integrating ICTs into instruction to a moderate $(47 \%)$ or a large $(24 \%)$ extent, whereas only $5 \%$ indicated they had no skills. Virtually identical results were obtained when they were asked if they were capable of teaching online reading skills (respectively, $46 \%$ to a moderate extent, $26 \%$ to a large extent, and $4 \%$ not at all). However, this confidence might inhibit integration if it is unrealistic or misguided. Teachers' confidence is also mitigated by the finding that many of them reported a relatively shallow view of integrating ICTs into instruction, based on simply 
using digital technologies rather than addressing specific curricular goals.

The results of this investigation also emphasize the fact that administrators and policymakers cannot expect teachers to bear the sole responsibility for increasing integration of ICTs into literacy instruction. They, too, must provide support. One obstacle to which administrators and policymakers might productively attend, for example, is arranging for additional professional development aimed specifically at how to integrate ICTs, given the extent to which curriculum standards and high-stakes assessments enhance or inhibit increased integration. Based on these findings and the conclusions they suggest, we recommend that calls for more integration of ICTs, such as those issued by IRA and NGTE, should acknowledge that administrators and policymakers have an important role in increasing integration.

The results also inform those interested in providing professional development aimed at assisting literacy teachers to increase the integration of ICTs. For example, the present study adds nuance to the frequent finding that teachers' beliefs influence actual use of technology. That is, literacy teachers apparently have a strong commitment to integrating 21st-century literacy skills into instruction, despite the fact that they do not spontaneously list those skills when asked to define integration of ICTs. Also, they apparently see integration more in technological, rather than curricular, terms that are more supplemental to instruction. Neither do they typically believe that new genres of reading and writing are important aspects of integrating ICTs into instruction. Appropriate professional development may need to construct only a relatively short bridge between narrower technological conceptualizations and the deeper curricular commitments and understandings that IRA and NCTE have advocated. More research is needed to investigate that possibility.

The findings and conclusions of the present study must be interpreted in light of a few caveats. First, although Internet surveys are a useful new tool, rarely do they permit a truly random sample, nor do they permit a precise computation of response rates (Sue \& Ritter, 2007). Nonetheless, that does not invalidate the use of such surveys, nor the preliminary insights and directions they may suggest for further study (Sue \& Ritter, 2007). Similarly, surveying literacy teachers who are not members of a professional organization such as IRA would usefully extend the findings of the present study. A related caveat is that teachers' perceptions about integrating ICTs into instruction and their selfreported use may not be entirely accurate. The data reported here would be strengthened by observational data to verify consistency between teachers' perceptions, reported use, and actual practice.
Another caveat is that the intent of the present investigation was to provide a broad backdrop to inform more narrowly focused studies in the future. Interpretations and conclusions reported here must be viewed in that light. Future studies might take a more fine-grained approach examining, for example, whether our conclusions hold for teachers in the primary, elementary, or middle school grades. 1,2 Such studies might also include demographic information on race and class. In the present study, we decided not to conduct such a fine-grained analysis of the data because (a) it was unwieldy to do so in a single report, (b) our purpose was to gain a broad understanding of literacy teachers as a cohort, and (c) it would have weakened the power of our path analysis. Nonetheless, the results reported here provide a firm basis from which such comparisons might be launched.

A final caveat is that a model tested in path analysis, even though it is often described as a causal model, does not establish causation. As Everitt and Dunn (1991) noted, "However convincing, respectable and reasonable a path diagram...may appear, any causal inferences extracted are rarely more than a form of statistical fantasy" (p. 108). However, the model tested in the present study reveals statistical relationships firmly grounded in the data. Our results suggest possible connections that can lay the groundwork for additional studies and other methodological approaches and suggest directions for, and the content of, professional development.

Despite these caveats, we believe the present study advances understanding of the extent to which ICTs are being integrated into literacy instruction and what factors should be considered toward profitably increasing integration, consistent with expanding definitions of literacy. It might also serve as a benchmark to determine progress toward increasing integration and lead to the development of assessments measuring propensity to integrate ICTs into literacy instruction. Finally, we believe that the current study addresses Lawless and Pellegrino's (2007) conclusion, from a review of the literature related to integrating technology into instruction, that "We need to move to a more systematic study of how technology integration occurs within our schools, what increases its adoption by teachers, and the long-term impacts that these investments have on both teachers and students" (p. 575). We agree and believe that there is no area of the curriculum more important than literacy instruction for which that conclusion is warranted.

\footnotetext{
Notes

${ }^{1}$ Because there were substantially fewer grade 10-12 teachers than K-9 teachers (see Table 1), we conducted an analysis to determine if the results would be statistically different without grade 10-12 teachers. We ran separate correlations for these respective
} 
groups for each of the factors established in the exploratory factor analysis. The correlations for each group of teachers followed virtually the same direction and pattern. Further, all of the factors identified when the analysis was conducted with both groups together remained significantly correlated, and all but one of the items were correlated in the same direction. Thus, we determined that the results and conclusions would not be affected by removing the grade 10-12 teachers from the analysis.

${ }^{2}$ For example, although it was beyond the scope of the present study to parse the data by grade level, we found a statistically significant difference in the extent of ICT integration between teachers in grades $\mathrm{K}-3$ and teachers in grades $4-6$ and $7-12$. Thus, some of the results and conclusions reported here, which apply to literacy teachers in general, may need to be modified for teachers at a particular grade level.

\section{References}

Angers, J., \& Machtmes, K. (2005). An ethnographic-case study of beliefs, context factors, and practices of teachers integrating technology. Qualitative Report, 10(4), 771-794.

Bauer, J., \& Kenton, J. (2005). Toward technology integration in the schools: Why it isn't happening. Journal of Technology and Teacher Education, 13(4), 519-546.

Baumann, J., \& Bason, J. (2011). Survey research. In N. Duke \& M. Mallette (Eds.), Literacy research methodologies (2nd ed., pp. 404-426). New York: Guilford.

Becker, H.J. (1994). How exemplary computer-using teachers differ from other teachers: Implications for realizing the potential of computers in schools. Journal of Research on Computing in Education, 26(3), 291-321.

Becker, H.J. (1999). Internet use by teachers: Conditions of professional use and teacher-directed student use. Teaching, learning, and computing: 1998 National Survey. (Report No. 1). Irvine: Genter for Research on Information Technology and Organizations, University of California.

Bruce, B.C., \& Rubin, A. (1993). Electronic quills: A situated evaluation of using computers for writing in the classroom. Hillsdale, NJ: Erlbaum.

Christensen, R., \& Knezek, G. (2002). Instruments for assessing the impact of technology in education. Computers in the Schools, 18 (2), 5-25.

Clark, G.M., \& Peterson, P.L. (1986). Teachers' thought processes. In M.G. Wittrock (Ed.), Handbook of research on teaching (pp. 255-296). New York: Macmillan.

Coiro, J., Knobel, M., Lankshear, G., \& Leu, D. (2008). Central issues in new literacies and new literacies research. In J. Coiro, M. Knobel, C. Lankshear \& D. Leu (Eds.), Handbook of research on new literacies (pp. 1-22). New York: Lawrence Erlbaum.

Craig, D. (1997). Telecurricular teaching and learning the impact of world-wide web access on the instructional process. Telecommunications in Education, 8(3), 6-8.

Crawford, S.D., Couper, M.P., \& Lamias, M.J. (2001). Web surveys: Perception of burden. Social Science Computer Review, 19 (2), 146-162.

Cuban, L. (2001). Oversold and underused: Computers in the classroom. Cambridge, MA: Harvard University Press.

Dillman, D., Smyth, J., \& Christian, L.M. (2009). Internet, mail and mixed-mode surveys: The tailored design method (3rd ed.). Hoboken, NJ: Wiley.

Dillman, D.A. (2007). Mail and Internet surveys: The tailored design method (2nd ed.). Hoboken, NJ: Wiley.

Dockstader, J. (1999). Teachers of the 21st century know the what, why and how of technology integration. T.H.E. Journal, 26(6), $73-74$

Efron, B., \& Tibshirani, R. (1993). An introduction to bootstrap. London: Chapman and Hall.
Ertmer, P. (2005). Teacher pedagogical beliefs: The final frontier in our quest for technology integration. Educational Technology Research and Development, 53(4), 25-39.

Ertmer, P., Addison, P., Lane, M., Ross, E., \& Woods, D. (1999). Examining teachers' beliefs about the role of technology in the elementary classroom. Journal of Research on Computing in Education, 32(1), 54-72.

Ertmer, P., \& Ottenbreit-Leftwich, A. (2010). Teacher technology change: How knowledge, confidence, beliefs, and culture intersect. Journal of Research on Technology in Education, 42(3), 255-284.

Ertmer, P., Gopalakrishnan, S., \& Ross, E.M. (2001). Technologyusing teachers: Comparing perceptions of exemplary technology use to best practices [Electronic version]. Journal of Research on Technology in Education, 33(5).

Everitt, B.S., \& Dunn, G.G. (1991). Applied multivariate data analysis. London: Edward Arnold.

Fatemi, E. (1999). Building the digital curriculum: Summary. Education Week, 19(4), 5-8.

Garner, R., \& Gillingham, M.G. (1996). Internet communications in six classrooms: Conversations across time, space, and culture. Mahwah, NJ: Erlbaum.

Harris, J., Mishra, P., \& Koehler, M. J. (2009). Teachers' technological pedagogical content knowledge and learning activity types: Curriculum-based technology integration reframed. Journal of Research on Technology in Education, 41(4), 393-416.

Hermans, R., Tondeur, J., van Braak, J., \& Valcke, M. (2008). The impact of primary school teachers' educational beliefs on the classroom use of computers. Computers $\mathcal{E}$ Education, 51(4), 1499-1509.

Honan, E. (2008). Barriers to teachers using digital texts of literacy classrooms. Literacy, 42(1), 36-43.

Hughes, J.E., Kerr, S.P., \& Ooms, A. (2005). Content-focused technology inquiry groups: Cases of teacher learning and technology integration. Journal of Educational Computing Research, 32 (4), 367-379.

Hutchison, A., \& Reinking, D. (2010). A national survey of barriers to integrating information and communication technologies into literacy instruction. 59th yearbook of the National Reading Conference. Milwaukee, WI: National Reading Conference.

International Reading Association. (2009). New literacies and 21stcentury technologies: A position statement of the International Reading Association. Newark, DE: Author.

Karchmer, R. (2001). The journey ahead: Thirteen teachers report how the Internet influences literacy and literacy instruction in their K-12 classrooms. Reading Research Quarterly, 36(4), 442466

Kist, W. (2007). Basement new literacies: Dialogue with a first-year teacher. English Journal, 97(1), 43-48.

Kress, G. (2003). Literacy in the new media age. London: Routledge.

Labbo, L.D., \& Reinking, D. (1999). Negotiating the multiple realities of technology in literacy research and instruction. Reading Research Quarterly, 34(4), 478-492.

Lankshear, C., \& Knobel, M. (2003). New literacies: Changing knowledge and classroom learning. Suffolk, UK: Open University Press.

Lawless, K., \& Pellegrino, J. (2007). Professional development in integrating technology into teaching and learning: Knowns, unknowns, and ways to pursue better questions and answers. Review of Educational Research, 77(4), 575-614.

Leu, D. (2006). New literacies, reading research, and the challenges of change: A deictic perspective. In J. Hoffman, D. Schallert, M. Fairbanks, J. Worthy \& B. Malloch (Eds.), 55th yearbook of the National Reading Conference (pp. 1-20). Oak Creek, WI: National Reading Conference.

Leu, D., Kinzer, G.K., Coiro, J., \& Cammack, D. (2004). Towards a theory of new literacies emerging from the Internet and other information and communication technologies. In R.B. Rudell \& N. Unrau (Eds.), Theoretical models and processes of reading (5th 
ed., pp. 1570-1613). Newark, DE: International Reading Association.

Leu, D., \& Reinking, D. (1996). Bringing insights from reading research to research on electronic learning environments. In H. van Oostendorp (Ed.), Cognitive aspects of electronic text processing (pp. 43-75). Norwood, NJ: Ablex.

Leu, D., Reinking, D., Carter, A., Castek, J.M., Coiro, J.L., \& Henry, L.A., et al. (2007, April) Defining online reading comprehension: Using think aloud verbal protocols to refine a preliminary model of Internet reading comprehension processes. Paper presented at the annual meeting of the American Educational Research Association, Chicago, IL.

Leu, D., Reinking, D., Hutchison, A., McVerry, G., O'Byrne, I., \& Zawilinski, L. (2009, May). Internet reciprocal teaching (IRT): A research-based model for teaching the new literacies of online reading comprehension. Symposium presented at the annual meeting of the International Reading Association, Minneapolis, MN.

Lewis, G., \& Fabos, B. (2005). Instant messaging, literacies, and social identities. Reading Research Quarterly, 40(4), 470-501.

Mallinckrodt, B., Abraham, T.W., Wei, M., \& Russell, D.W. (2006). Advance in testing statistical significance of mediation effects. Journal of Counseling Psychology, 53(3), 372-378.

McEneaney, J. (2006). Agent-based literacy theory. Reading Research Quarterly, 41(3), 352-371.

Muthén, L., \& Muthén, B. (2007). Mplus 5.2 [Computer software]. Los Angeles: Statmodel.

National Genter for Educational Statistics. (2003). Internet access in public schools and classrooms: 1994-2002. Retrieved June 27, 2011, from nces.ed.gov/pubs2004/2004011.pdf

Neuendorf, K. (2002). The content analysis guidebook. Thousand Oaks, CA: Sage.

Penuel, W.R., Boscardin, G.K., Masyn, K., \& Crawford, V. (2007). Teaching with student response systems in elementary and secondary education settings: A survey study. Educational Technology Research and Development, 55(4), 315-346.

Raine, L., \& Horrigan, J. (2005). A decade of adoption: How the Internet has woven itself into American life. Retrieved April 20, 2010, from www.pewinternet.org/Reports/2005/How-the-internethas-woven-itself-into-American-life.aspx.

Rea, L., \& Parker, R. (2005). Designing and conducting survey research: A comprehensive guide. San Francisco: Jossey-Bass.

Reinking, D. (1992). Differences between electronic and printed texts: An agenda for research. Journal of Educational Multimedia and Hypermedia, 1(1), 11-24.

Reinking, D. (1998). Synthesizing technological transformations of literacy in a post typographic world. In D. Reinking, M. McKenna, L.D. Labbo \& R. Kieffer (Eds.), Handbook of literacy and technology (pp. xi-xxx). Mahwah, NJ: Erlbaum.

Reinking, D. (2001). Multimedia and engaged reading in a digital world. In L. Verhoeven \& C.E. Snow (Eds.), Literacy and motivation: Reading engagement in individuals and groups (pp. 195-221). Mahwah, NJ: Erlbaum.

Reinking, D., \& Bradley, B.A. (2008). On formative and design experiments: Approaches to language and literacy research. New York: Teachers College Press.
Reinking, D., Labbo, L.D., \& McKenna, M.C. (2000). From assimilation to accommodation: A developmental framework for integrating digital technologies into literacy research and instruction. Journal of Research in Reading, 23(2), 110-122.

Schaefer, D., \& Dillman, D. (1998). Development of a standard e-mail methodology: Results of an experiment. Public Opinion Quarterly, 62(3), 378-397.

Scott, S.M., Chovanec, D.M., \& Young, B. (1993). Philosophyin-action in university teaching. Proceedings of the 34th Annual Adult Education Research Conference, University Park: Penn State University.

Shrout, P.E., \& Bolger, N. (2002). Mediation in experimental and nonexperimental studies: New procedures and recommendations. Psychological Methods, 7(4), 422-445.

SPSS for Windows. (2010). Rel. 19.0. [Computer software]. Chicago: SPSS Inc.

Stolle, E. (2008). Teachers, literacy, \& technology: Tensions, complexities, conceptualizations \& practice. In Y. Kim, V. Risko, D. Compton, D. Dickinson, M. Hundley, R. Jimenez, K. Leander \& D. Wells-Rowe (Eds.), 57th yearbook of the National Reading Conference (pp. 56-69). Oak Creek, WI: National Reading Conference.

Sue, V.M., \& Ritter, L.A. (2007). Conducting online surveys. Thousand Oaks, CA: Sage.

United States Department of Education. (2003). Federal funding for educational technology and how it is used in the classroom: A summary of findings from the integrated studies of educational technology. Washington, D.C.: Office of the Under Secretary, Policy and Program Studies Service.

Warschauer, M., Knobel, M., \& Stone, L.A. (2004). Technology and equity in schooling: Deconstructing the digital divide. Educational Policy, 18(4), 562-588.

Wells, J., \& Lewis, L. (2006). Internet access in U.S. public schools and classrooms: 1994-2005. Washington, DC: National Center for Education Statistics.

Windschitl, M., \& Sahl, K. (2002). Tracing teachers' use of technology in a laptop computer school: The interplay of teacher beliefs, social dynamics, and institutional culture. American Educational Research Journal, 39(1), 165-205.

Zhao, Y., Pugh, K., Sheldon, S., \& Byers, J. (2002). Conditions for classroom technology innovations. Teachers College Record, 104 (3), 482-515.

Submitted April 22, 2010

Final revision received May 3, 2011

Accepted May 16, 2011

Amy Hutchison is an assistant professor of literacy at lowa State University, Ames, USA; e-mail amyhutch@iastate.edu.

David Reinking is the Eugene T. Moore Professor of Teacher Education at Clemson University, South Carolina, USA; e-mail reinkin@clemson.edu. 